\title{
ISOCHRON TRANSLATION AND A GEOLOGICAL CRITERION TO DECLARE AN ISOCHRON*
}

\author{
L. R. K. PERERA \\ Department of Geology, University of Peradeniya, Peradeniya, Sri Lanka \\ (keerthip@pdn.ac.lk)
}

(Received $5^{\text {th }}$ June 2020; accepted $29^{\text {th }}$ September 2020)

\begin{abstract}
Isochron is an equal-age line for measured present-day parent and daughter isotopic ratios of co-genetic minerals and rocks plotted on an isochron diagram. Isochrons provide ages and initial isotopic ratios of the samples useful to understand their geological evolution. However, the statistical criterion used to declare an isochron cannot guarantee the co-genesis of the samples. During eight decades of application of the isochron method of dating, a geological criterion did not emerge because the process of isotopic resetting in metamorphic rocks has not been investigated in its real perspective. Thus, isochron rotation in isochron diagrams was envisaged during isotopic resetting though incompletely reset whole-rocks and minerals suggest isochron translation. In such rocks, an isochron appears to have moved or translated parallel to itself on the isochron diagram during partial resetting enveloping a data scatter between sub-parallel lines. Here isochron translation has been confirmed using computer simulations of whole-rock isotopic resetting. Isochron translation proceeding in three distinct stages establishes a Field Gradient of Initial Ratios (FGIR) in the third stage, characteristic of co-genetic samples, useful as a geological criterion to declare an isochron. Isochron translation is a fingerprint of layer arrangement, layer thickness and isotopic composition of rocks, and enables (a) derivation of accurate isotopic ages, (b) re-evaluation of statistically rejected data, (c) resolving isotopic heterogeneities in the earth's crust and mantle, (d) evaluation of model ages and mineral ages.
\end{abstract}

Keywords: Isochron Translation, Co-genesis, Field Gradient of Initial Ratios, Mantle Heterogeneity, Model ages.

\section{INTRODUCTION}

Since 1940s isochron method of dating has been used to find geological ages of terrestrial and extraterrestrial materials (Hahn et al., 1943, Lugmair et al., 1975). Isochrons provide ages and initial isotopic ratios of crustal and mantle samples to identify crust formation ages, periods of crustal growth and onset of periods of metamorphism and tectonism (Moorbath, 1975a, b), infer evolution of the earth's mantle (Moorbath, 1977, DePaolo and Wasserburg, 1979, DePaolo, 1980, 1981) and isotopic heterogeneity in the mantle (McCulloch and Compston, 1981, Shirey and Hanson, 1986). Isochrons of meteorites, lunar samples, lunar and martian meteorites have been used to infer differentiation events on moon and mars (Rink and Thompson, 2015, Gaffney and Borg, 2014, Snyder et al., 1994, Borg et al., 1997) and primordial isotopic composition of the solar nebula (Papanastassiou and Wasserburg, 1969, Boyet et al., 2010). In practice, measured

${ }^{*}$ Dedicated to Professor Hiroo Kagami present -day isotopic ratios of minerals of a rock specimen, and/or co-genetic whole-rock specimens from one or more exposures several tens or hundreds of meters or tens of kms apart (Field and Raheim, 1979a, Aftalion and van Breemen, 1980, Black et al., 1983) producing a Best-Fit Line (BFL) with Mean Square of Weighted Deviates (MSWD) $\leq 1$ on an isochron diagram (Nicolaysen, 1961, Faure, 1966, Dickin, $1995)$ is considered an isochron. Whenever a BFL is within analytical error of the samples the MSWD is $\leq 1$, but geologically disturbed samples give an errorchron (MSWD > 1). Welldefined BFLs considered as isochrons, are sometimes mixing-lines (Faure, 1966, Dickin, 1995). Incomplete isotopic resetting leads to 'meaningless' isochrons, with an age intermediate between a primary event and a secondary event (Field and Raheim, 1979b). In geological literature examples abound where isochrons have been suggested after eliminating 
a few samples from regression analysis to improve MSWD of a BFL. Moreover, field and petrographic observations do not guarantee that samples are co-genetic, particularly in metamorphic rocks, since the length-scale and level of isotopic homogenization achieved during metamorphism are unknown. Waning $\mathrm{P}$, $\mathrm{T}$ conditions and/or less intense later geological events may have completely or partially reequilibrated the rocks, destroying the isotopic record of an event envisaged based on petrography (Field and Raheim, 1979a). The linear regression techniques available (York, 1969, McIntyre et al., 1966) for isotopic data analysis only attempt to weigh the relative significance of geological scatter in relation to analytical errors to arrive at a BFL, but are incapable of passing a judgment on the cogenesis or suggest that samples represent an isotopically homogenized volume. Geological criteria don't exist to ascertain whether a BFL with MSWD $\leq 1$ is truly an isochron. Thus, before making inferences on the geological evolution on the basis of initial isotopic ratios and geological ages, the BFLs have to undergo a close scrutiny to ascertain the co-genesis of samples, particularly if the material is metamorphic. Without such scrutiny, an uncertainty inevitably surrounds every isochron despite the perfectness of the line-fit on an isochron diagram. Since isotopic resetting has not been investigated in its true perspective, a geological criterion did not emerge to positively identify an isochron. In a $\mathrm{Rb}-\mathrm{Sr}$ and $\mathrm{Sm}-\mathrm{Nd}$ study of high-grade gneisses of Sri Lanka (Perera, 2015) isochrons appeared to have moved or translated parallel to themselves during incomplete isotopic resetting. Data of Field and Raheim (1979a) Aftalion and van Breemen (1980) Black et al (1983) from elsewhere suggested the same. Thus, simulations were performed on computer to investigate whether isochrons rotate or translate in isochron diagrams during isotopic resetting. Isochron translation was confirmed, and the process is described and illustrated here in detail to develop a geological criterion to positively identify an isochron. Applications of isochron translation facilitate better understanding of whole-rock and mineral isotopic systems. The procedures and notations used in the simulations are given in the Appendix.

\section{ISOCHRON TRANSLATION: THE SIMULATIONS OF WHOLE-ROCK ISOTOPIC RESETTING}

In the simulations, isochron translation follows three distinct stages during resetting of a wholerock isochron. They are, (i) Stage of local isotopic homogenization, (ii) Stage of establishment of a Field Gradient of Initial Ratios (FGIR), (iii) Stage of narrowing-down the FGIR, respectively (Fig. 1). These stages were encountered in all simulations studied by changing various parameters; namely, layer thickness, arrangement, isotopic composition, and protolith age. The salient characteristics of each stage are highlighted below and are illustrated in the Appendix figures.

\section{Stage 1: Local Isotopic Homogenization}

At the onset of resetting, an isochron is resolved into several sub-parallel clusters of data, each representing an individual layer, and begins to translate in the isochron diagram (Fig. 1(a), Movie S1). As resetting progressed, (a) a cluster of data is further resolved into subsets of data of similar slope each with a distinct initial ratio. Each subset is a layer parallel slice containing 36 samples (Fig. A1), (b) the subsets of data of a given layer translate in the diagram with respect to one another varying their initial ratios, (c) the subsets of different layers behave as distinct groups and begin to translate relative to one another. The translation of subsets and groups of subsets in the diagram followed a unique pattern determined by the arrangement and thicknesses of the layers. Further resetting aligned the subsets of data horizontally in the diagram suggesting isotopic homogenization within each subset (Fig. 1(b), Movie S1). Present-day data of each sub-set gave BFLs with MSWD $\leq 1$ and Probability of Fit $(\mathrm{PoF})=1$ indicating the resetting age used in the simulation (Table A1). All subsets collectively show the maximum range of initial ratios of local isotopic homogenization. Marking the end of stage 1, positive correlation between parent and daughter ratios among the different layers begins to disappear in the isochron diagram and initial ratios of groups of subsets of different layers start overlapping with each other. 


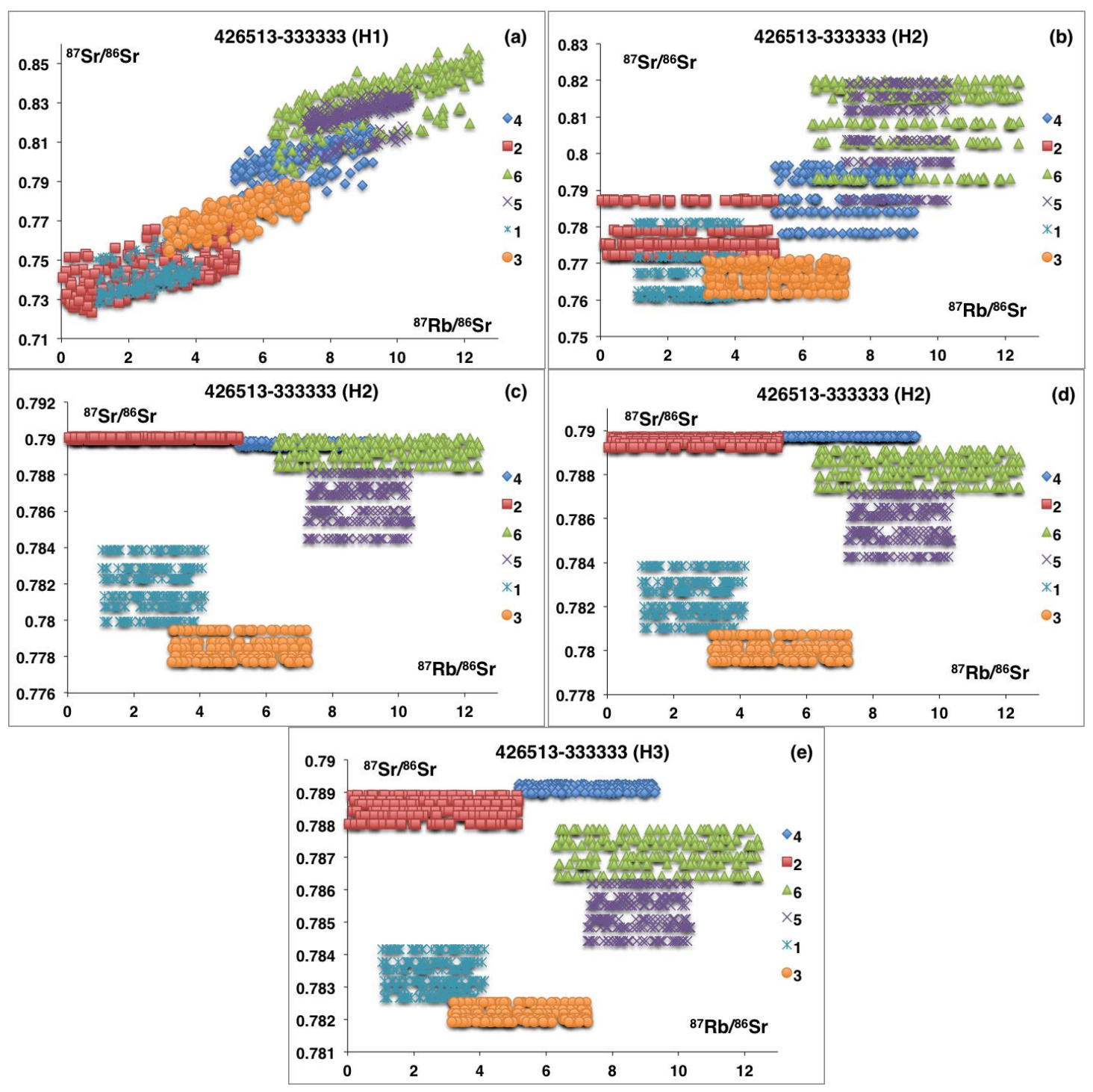

Fig. 1. The three stages of isochron translation and their salient features. (a) Onset of isotopic resetting in Stage 1, (b) An early stage 2, showing data subsets of local isotopic homogenization and wide and overlapping ranges of initial ratios of different layers, $(c, d)$ Late Stage 2, note short-lived isotopic homogenization in layers 2 and 4 and a partially developed FGIR between layers 6,5,1,3. (e) Early Stage 3, the fully developed FGIR and ${ }^{87} \mathrm{Sr}{ }^{86} \mathrm{Sr}$ homogenized at second decimal (see Appendix).

\section{Stage 2: Establishment of a Field Gradient of Initial Ratios (FGIR)}

Further resetting strives to reduce the range of initial ratios of subsets observed at the end of stage 1 (Movie S1). While groups of subsets of different layers translate in the isochron diagram, subsets within a group also translate with respect to one another to develop an initial ratio gradient within a layer. This leads to Culmination of Isochron Translation (CIT) during which the initial ratio gradients of different layers coalesce to develop a Field Gradient of Initial Ratios (FGIR) across all the layers. Thus, at the CIT, groups of subsets of different layers have translated in the isochron diagram to arrange their data in natural order reflecting the arrangement of layers (Fig. 2(a)(f), Fig. A2). This happens irrespective of the isotopic compositions, the thicknesses and the geological ages of the layers. A partially developed FGIR (i.e. only across a majority of layers of a succession) (Fig. 1(c), (d)) may exist while a given volume is nearing the CIT. Figures 2(a)-(f) and Fig. A2 show the variations of initial ratios of subsets of all layers throughout stage 2 and the development of a FGIR across a six-layer arrangement. The FGIR 
in an isochron diagram at CIT may be inverted depending on (i) layer arrangement of the same set of layers (Fig. 3), (ii) the layer thicknesses even for a fixed layer arrangement (Fig. 4). Establishment of a FGIR at CIT eliminates the overlaps between initial ratios of different layers observed during the stages 1 and 2 . The pattern of isochron translation, variations of daughter isotopic composition encountered by the layers, time spent to reach the CIT and the levels of isotopic homogenization at CIT vary between different layer arrangements and their isotopic composition and extent of the process (Figs. A3, A4). Irrespective of the various parameters employed, all simulations developed a FGIR at CIT confirming that isochron translation is a fingerprint of the layer arrangement and isotopic composition. During isochron translation,

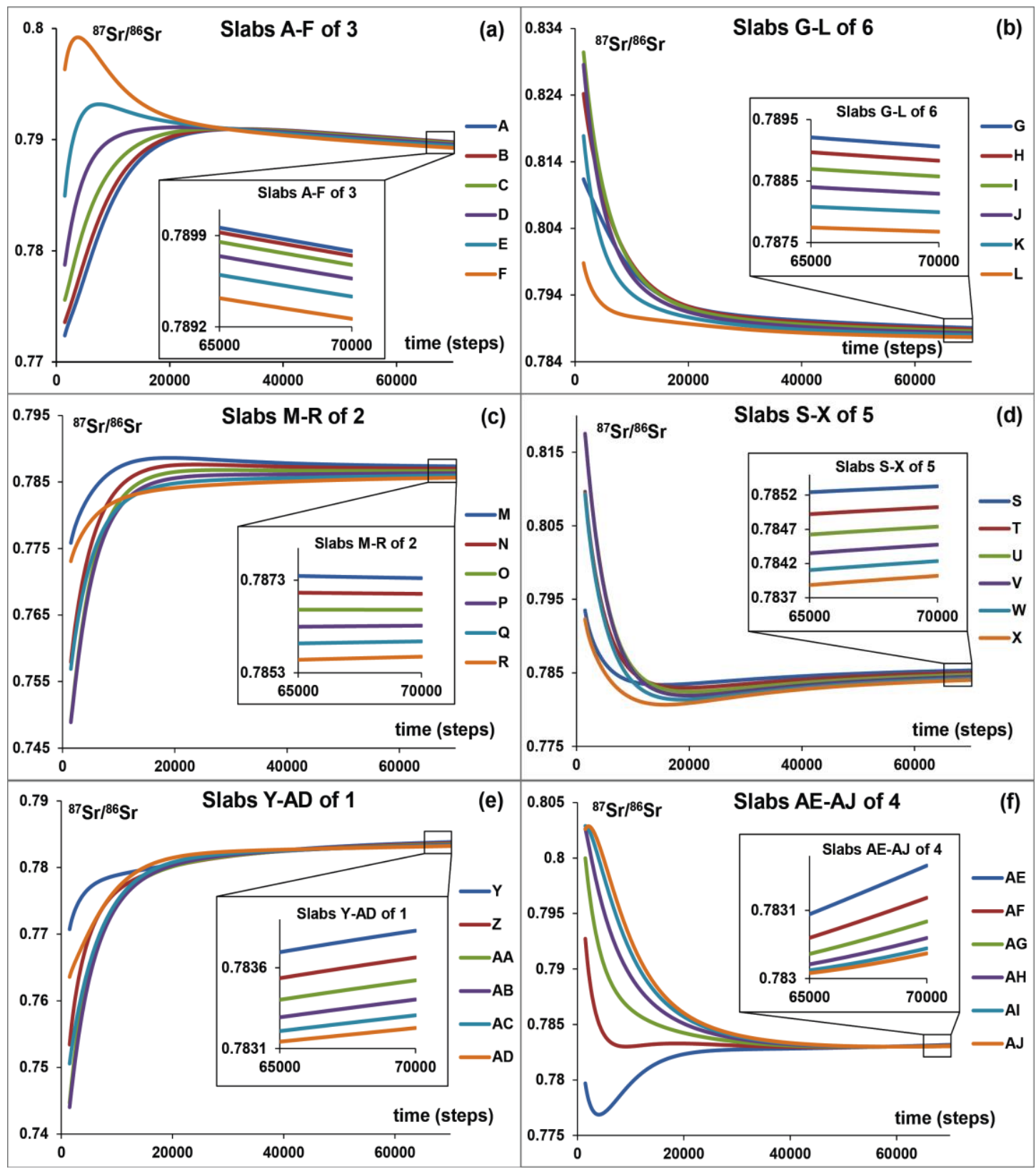

Figs. 2 (a)-(f). Variations of initial ratios of local ${ }^{87} \mathrm{Sr}{ }^{86} \mathrm{Sr}$ homogenization during Stage 2. The initial ratios of the six slabs of each layer of the arrangement 362514-333333 develop an initial ratio gradient during stage 2. These gradients coalesce to produce the FGIR across all layers from slab A to AJ shown in the composite Fig. A2. The inset diagrams after 70,000 steps show the gradients following the physical order of the slabs given in the legend and also in Fig. Al. Note the symmetries between $(a) \&(f),(b) \&(e)$, and $(c) \&(d)$. 


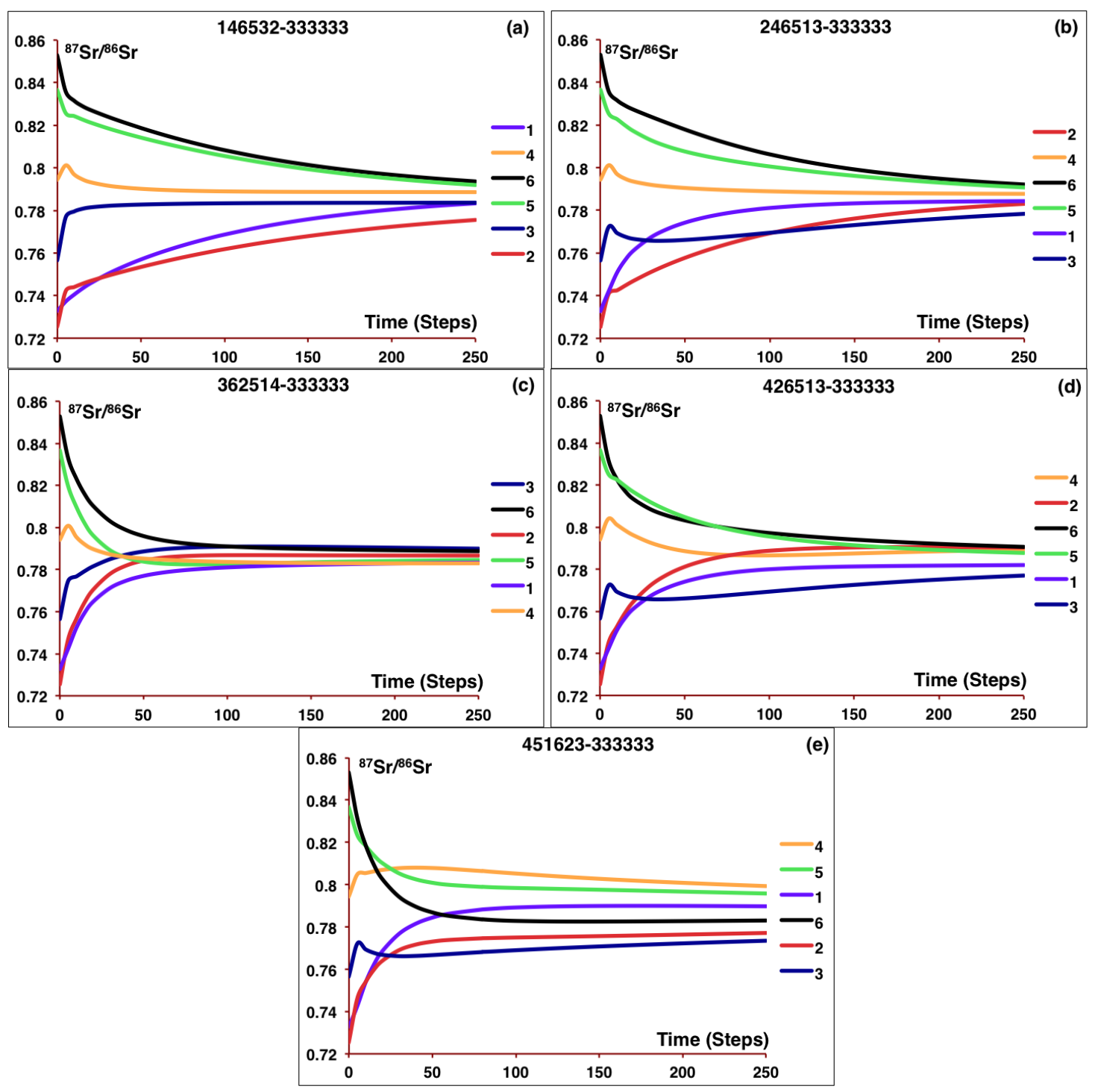

Fig. 3. Isochron translation as determined by layer arrangement ${ }^{87} \mathrm{Sr} /{ }^{86} \mathrm{Sr}$ - time paths of the same six samples (one from each layer) in five six-layer arrangements of the same layers. The arrangement of samples within a layer and their parent ratios remain fixed. In (e), the layers reach CIT after 70 steps but ${ }^{87} \mathrm{Sr}{ }^{86} \mathrm{Sr}$ are not homogenized even at the first decimal. Among others only $(c)$ reaches CIT at 350 steps and $(a),(b),(d)$ even later than that.

a layer having a low or intermediate range of parent ratios may possesses the highest daughter ratio at CIT (Fig. A4(i), Movie S1). A layerwide homogenization in one or both marginal layers of any arrangement commonly occurs here irrespective of layer thicknesses and their ranges of parent ratios. This occurs before reaching the CIT, sometimes, in one or two inner layers of a sequence too (Fig. 1(c), (d)). In the Movie S1, the marginal layers 3 and 4, and the inner layer 1 demonstrate this. These layer-wide homogenizations are short-lived but their present-day data give perfect isochrons (MSWD $<1)$ indicating the resetting age, thus, are called 'flash' isochrons (Table A2). Meanwhile the local isotopic homogenization within each subset continues to improve during stage 2 and homogenize daughter ratios at 13-14 decimal places. Isochrons produced by subsets are 'transient' isochrons since those are open isotopic systems (residing in a closed system) changing their initial ratios throughout (Movie S1, Fig. 2(a)-(f)). 


\section{Stage 3: Narrowing-down of FGIR}

Relative positions of groups of sub-sets of data of all layers remain fixed during stage 3 for all layer arrangements (Fig. 1(e)). The FGIR established at CIT is gradually narrowed-down during this stage (Movie S1) but the length of time it takes depends on the extent to which the layers homogenized at the CIT for a given time gap between the primary event and the resetting event. Time taken also varies between different layer arrangements of the same layers. In some arrangements daughter ratios may not have homogenized even at the first decimal whereas in another the ratios may homogenize at fifth decimal at the CIT. Even after an advanced stage (ex. $6^{\text {th }}$ decimal) of isotopic homogenization within stage 3, the FGIR remains across all layers, thus it can be used to identify a wholerock volume that reached the third stage.

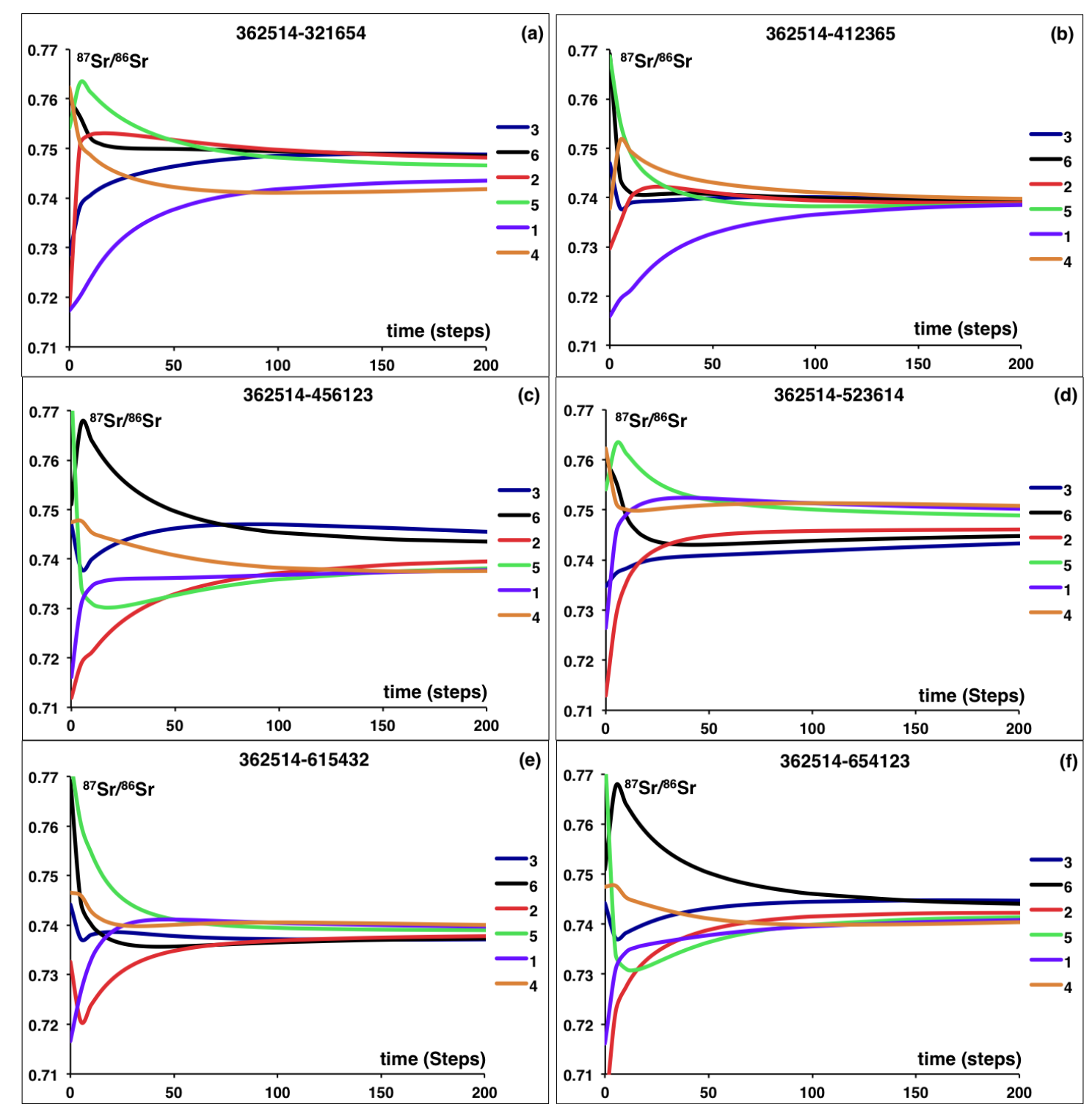

Fig. 4. Variation of isochron translation with layer thickness in the arrangement 362514. The ${ }^{87} \mathrm{Sr}{ }^{86} \mathrm{Sr}$ - time paths of six different combinations of layer thicknesses (a $3.5 \mathrm{Ga}$ isochron is reset at $3.0 \mathrm{Ga}$ ). Here the representative sample of each layer, occupies a mid-layer position besides the central axis through a column consisting of 42 slabs from A to AP (Fig. A1). The range of parent ratios of a layer remains fixed. In (b), the ${ }^{87} \mathrm{Sr}{ }^{86} \mathrm{Sr}$ ratios appear homogenized at step 200 but those reach CIT after 600 steps, whereas all others reach the CIT at or just after 200 steps. In (a), (c), $(f)$ the FGIR is following the layer arrangement at CIT, and in $(d),(e)$ the FGIR is in reverse order or inverted at CIT. 


\section{Isochron Translation: Present-day views}

The three stages of isochron translation are not easy to distinguish on a present-day isochron diagram (Figs. A3, A4, Movie S2). Their distinction is vague even in the $\mathrm{Rb}-\mathrm{Sr}$ system for a time gap of $1 \mathrm{Ga}$ between the initial isochron and the resetting event. In the case of $\mathrm{Sm}-\mathrm{Nd}$, where present-day daughter ratios of crustal rocks vary beyond $2^{\text {nd }}$ or $3^{\text {rd }}$ decimal, even a gap of $1 \mathrm{Ga}$ is inadequate. Thus, isochron translation has not been recognized and understood based on natural data during the last eight (08) decades of application of the isochron method of dating.

At the onset of resetting, isotopic data begin to translate and layers with high parent ratios will give high initial ratios producing a step-like appearance on a present-day isochron diagram. The step-like feature is prominent if the overlap of parent ratios of the different layers is minimal and the layers are of equal thickness. When the overlap of parent ratios and the differences in layer thicknesses are significant, the step-like feature goes beyond recognition. As resetting progresses the steps disappear and the positive correlation between parent and daughter ratios is gradually lost and the scatter of data is at a maximum since the range of initial ratios of local homogenization of sub-sets is maximized. The width of the area of data scatter depends on the time gap between the primary event and the resetting event, the ranges of parent isotopic ratios of the layers and their extent of overlap. Resetting progressing in stage 2 gradually eliminates the differences in initial ratios of local isochrons to narrow down the data scatter. In the present-day isochron diagram of stage 3 the data scatter is proportional to the extent to which isotopic homogenization has been achieved, and its trend produces a slope approximating the age of the resetting event.

\section{RESULTS AND DISCUSSION}

\section{MSWD and PoF of BFLs rely on too many factors}

Details of BFLs for data from different stages of isotopic resetting in six- and eighteen-layer arrangements are summarized in Appendix Tables A3-5. MSWD and PoF of BFLs rely on many factors is evident from the tables. They are, the number of samples collected, the layer arrangement, length-scale of isotopic resetting, the $2 \sigma$ percentage errors used in the calculations, the main controlling factor being the level of isotopic homogenization achieved at a given step of resetting. Table A3 shows that a small number of samples collected from stage 1 widened the ranges of isotopic ages and MSWD, and some BFLs were encountered with MSWD $<1$ and high PoF. This is even likely for $\mathrm{Rb}-\mathrm{Sr}$ system if the time gap between primary and resetting events is $\leq 0.5 \mathrm{Ga}$. $\mathrm{Rb}-\mathrm{Sr}$ data from the first and second stages of isochron translation gave Model 3 solutions (Ludwig, 2008). The BFLs had very high MSWD even at the largest $2 \sigma$ errors of $0.01 \%$ of ${ }^{87} \mathrm{Sr} /{ }^{86} \mathrm{Sr}$ ratios. The slopes of those lines never suggested the resetting age of the simulations. PoF of BFLs exceeded zero and a majority of those had MSWD > 1 after the ${ }^{87} \mathrm{Sr} /{ }^{86} \mathrm{Sr}$ ratios have been homogenized at the second decimal within the third stage. The PoF of BFLs reached 1.0 and the MSWD $<1$ when ${ }^{87} \mathrm{Sr} /{ }^{86} \mathrm{Sr}$ ratios are nearing homogenization at the third decimal. At the $2 \sigma$ errors of $0.01 \%$, $0.0044 \%$ and $0.0025 \%$ of ${ }^{87} \mathrm{Sr} /{ }^{86} \mathrm{Sr}$ ratios, the BFLs did not show large differences in MSWD after the PoF has reached 1.0 (Table A4(a)). MSWD $=0.12$ is a threshold value in six-layer arrangements at which $\mathrm{PoF}=1.0$ at all three $2 \sigma$ errors used. The BFLs of the eighteen-layer arrangement studied gave MSWD $\leq 0.38$ and $\mathrm{PoF}=1.0$ at all three $2 \sigma$ errors used when ${ }^{87} \mathrm{Sr} /{ }^{86} \mathrm{Sr}$ ratios have homogenized at the third decimal (Table A5(a), Fig. A5).

Sm-Nd data from the first and second stages gave Model 3 solutions and the BFLs had low but MSWD > 1. But some BFLs gave MSWD 1 and very low PoF for data from the first stage at $2 \sigma$ error of $0.01 \%$ of the ${ }^{143} \mathrm{Nd} /{ }^{144} \mathrm{Nd}$ ratios. However, MSWD is $>1$ and $\mathrm{PoF}=0$ for data representing the first and second stages of isochron translation for $2 \sigma$ errors of $0.0044 \%$ and $0.0025 \%$ (Table A4(b)). At the latter $2 \sigma$ errors, the PoF exceeds zero only when the ${ }^{143} \mathrm{Nd} /{ }^{144} \mathrm{Nd}$ ratios have homogenized at the fourth decimal. The arrangement 146532 is an exception where its ${ }^{143} \mathrm{Nd} /{ }^{144} \mathrm{Nd}$ ratios nearly homogenized at the fifth decimal mid-way within the second stage and $52 \%$ of BFLs showed a PoF of 1.0 and MSWD $<1$ even at $2 \sigma$ errors of $0.0025 \%$. Its Nd-ratios homogenized at the fifth decimal and all BFLs showed PoF of 1.0 and $\mathrm{MSWD}<1$ for all $2 \sigma$ errors used before reaching the CIT. In the Sm-Nd systems of other six-layer arrangements, BFLs gave MSWD $<1$ at all $2 \sigma$ errors and showed a PoF of 1.0 after ${ }^{143} \mathrm{Nd} /{ }^{144} \mathrm{Nd}$ ratios have homogenized at the fifth decimal within the third stage. An eighteen-layer 
arrangement of $3.5 \mathrm{Ga}$ old rocks was subject to Nd-isotopic resetting at $2.5 \mathrm{Ga}$. BFLs for that system were also analyzed at different steps of resetting until a probability fit of 1.0 was achieved (Fig. A6, Table A5(b)).

In the application of the isochron method to metamorphic rocks one assumes co-genesis or isotopic homogenization over the length-scale of sampling. In the simulations, protolith and resetting ages of rocks and the length-scale of isotopic homogenization are known and one exactly knows the level of isotopic homogenization in the samples collected at any stage. Therefore, details of BFLs for present-day data collected at chosen steps from the three stages of isochron translation facilitate a better understanding of the current practice of the isochron method. Tables A4(a), (b) summarized the details of BFLs from small length-scale (sixlayer) $\mathrm{Rb}-\mathrm{Sr}$ and $\mathrm{Sm}-\mathrm{Nd}$ isotopic systems at different stages of isotopic resetting. Table A5 (a) \& (b) summarized similar details for large length-scale (eighteen-layer) $\mathrm{Rb}-\mathrm{Sr}$ and $\mathrm{Sm}-\mathrm{Nd}$ isotopic systems. The rate of isotopic exchange used in six-layer arrangements is small compared to those in eighteen-layer arrangements. Thus, results shown at identical steps in Tables A4(a) \& (b) are not directly comparable with those in Tables A5(a) \& (b). But even at a large rate of isotopic exchange used, eighteen-layer arrangements took longer time to reach a given milestone (ex. CIT) compared to six-layer systems. In the $\mathrm{Rb}-\mathrm{Sr}$ system, the MSWD of BFLs is not sensitive to $2 \sigma$ percentage errors used after the PoF has reached 1.0, but it is not so in the Sm-Nd system (Tables A4(a), (b) and A5(a), (b)). Only the BFLs from the Sm-Nd system gave MSWDs $~ 1$ at $2 \sigma 0.01 \%$ error for stage 1 of isochron translation when hundred sets of data was randomly collected from six-layer simulations. However, data capable of producing linear alignments with MSWD $\sim 1$ at $2 \sigma 0.01 \%$ error do exist for stage 1 in the $\mathrm{Rb}-\mathrm{Sr}$ system. This was noted when the computer was commanded to pick samples fitting a line with a given slope and initial ratio. Always it picked more than 40 analyses satisfying the requirement out of a population of 1296 samples used in a six-layer simulation. This suggests that the probability of encountering a BFL with MSWD 1 within a hundred set of data collected during random sampling is extremely low due to large scatter of data on the isochron diagram. Both eighteenlayer $\mathrm{Rb}-\mathrm{Sr}$ and $\mathrm{Sm}-\mathrm{Nd}$ systems did not give
BFLs with MSWD 1 at $2 \sigma 0.01 \%$ error for stage 1 . This perhaps could be the result of large number (36) of samples collected for a given BFL (Tables A3, A5(a) \& (b)). But like in the six- layer arrangements data capable of producing MSWD $\sim 1$ at $2 \sigma 0.01 \%$ error do exist if the slope and the initial ratio are prescribed. Among the set of hundred BFLs for data at a chosen step within the stage 3, there are BFLs giving a mean age identical to the resetting age used in the simulations but their MSWD > 1. Some other BFLs give mean ages deviating from the resetting age, and some of those have low MSWD compared to those giving the resetting age. The Table A6 summarizes the two kinds of BFLs at two steps of resetting in the $3^{\text {rd }}$ Stage. If one relies only on MSWD to identify an isochron in natural rocks where the age of resetting is unknown, the BFLs deviating from the true resetting age will be preferred instead of those giving the true resetting age. In a later table the FGIR has been used to derive the resetting age using data from both kinds of BFLs mentioned above.

Naturally, both MSWD and PoF of BFLs improve for a fixed number of samples collected as resetting progresses, but in whole-rock volumes containing identical rocks some layer arrangements give narrow ranges of MSWD compared to others at identical steps of resetting (Tables A4(a), (b)). Large $2 \sigma$ percentage errors on daughter ratios give small values of MSWD and vice versa. Large length-scales give wide ranges and take long time to improve MSWD and PoF (Tables A5(a), (b)). Thus, PoF of BFLs reached 1.0 and the MSWD $<1$ within stage 3 at all $2 \sigma$ errors used, when ${ }^{87} \mathrm{Sr} /{ }^{86} \mathrm{Sr}$ ratios are nearing homogenization at the third decimal and ${ }^{143} \mathrm{Nd} /{ }^{144} \mathrm{Nd}$ are nearing homogenization at the fifth decimal in all six-layer systems but not in eighteen-layer systems. 146532 is an exception where ${ }^{143} \mathrm{Nd} /{ }^{144} \mathrm{Nd}$ homogenized at fifth decimal in stage 2 (Tables A4(a) \& (b)). Within $1 \mathrm{Ga}$, ${ }^{143} \mathrm{Nd} /{ }^{144} \mathrm{Nd}$ of a rock evolves at the third decimal and ${ }^{87} \mathrm{Sr} /{ }^{86} \mathrm{Sr}$ evolves at place of ones or first decimal. Thus, homogenization of ${ }^{143} \mathrm{Nd} /{ }^{144} \mathrm{Nd}$ at the fifth decimal is virtually equivalent to homogenization of ${ }^{87} \mathrm{Sr} /{ }^{86} \mathrm{Sr}$ at the third decimal since ${ }^{143} \mathrm{Nd} /{ }^{144} \mathrm{Nd}$ of crustal/mantle material are 'homogenized' at second decimal. This is in agreement with the said outcome of simulations. In the simulations, MSWD $\leq 1$ was reached in the Sm-Nd system ahead of $\mathrm{Rb}-\mathrm{Sr}$, despite identical rates of isotopic exchange, suggesting isotopic systems' control on it 
(Tables A4(a) \& (b)). When the daughter ratios are strongly homogenized, there is a threshold MSWD for a given number of samples collected, below which the PoF remains equal to 1. At that point MSWD is not sensitive to the $2 \sigma$ errors used. Thus, simulations suggest that the use of $0.01 \%$ error is appropriate only if that threshold has been reached, i.e. only for perfect isochrons. The threshold MSWD goes up with long length-scales of homogenization. In Tables A4(a), (b) a given arrangement gave a PoF of 1.0 at all three $2 \sigma$ errors used for a majority of BFLs at the last step sampled. Then six-layer Sm-Nd systems gave threshold MSWDs of < $0.0078(0.01 \%), 0.04(0.0044 \%)$ and 0.13 $(0.0025 \%)$ for perfect isochrons. In the $\mathrm{Rb}-\mathrm{Sr}$ system the threshold MSWD $=0.12$ at all $2 \sigma$ for six-layer systems. For eighteen-layer Sm-Nd and $\mathrm{Rb}-\mathrm{Sr}$ systems threshold MSWDs are $<0.017$ $(0.01 \%), 0.089(0.0044 \%), 0.27(0.0025 \%)$ and $\leq 0.38$ at all $2 \sigma$ respectively (Tables A5(a), (b), Figs. A5, A6). The above indicates that MSWD is controlled by too many factors, some hitherto unknown, and MSWD $\leq 1$ does not suggest isotopic homogenization unless $\mathrm{PoF}=1$.

Moorbath et al (1997) discussed Bennet et al's (1993) derivation of a range of $\varepsilon \mathrm{Nd}$ from +4.5 to -4.5 in the Archaean mantle and reported a BFL giving an age of $3371 \pm 59 \mathrm{Ma}(\varepsilon \mathrm{Nd}=-5.6 \pm 0.7$, MSWD $=9.2$ at $2 \sigma-0.0044 \%$ ) for 34 samples of Acasta gneisses. The BFL was attributed to a near complete $\mathrm{Nd}$-isotopic homogenization in 4 - 3.6 Ga old protoliths at 3.37 Ga and the large MSWD to initial $\varepsilon N d$ heterogeneities of protoliths or post $3.37 \mathrm{Ga}$ disturbances. An eighteen-layer simulation was performed assuming derivation of protoliths from CHUR and was reset at $3.37 \mathrm{Ga}$. A hundred set of 36sample BFLs for present-day data gave ages from 3.37 Ga to 3.94 Ga and MSWD from 8.9 to 9.3 (at $2 \sigma-0.0044 \%$ used by Moorbath et al) and $\mathrm{PoF}=0$, as ${ }^{143} \mathrm{Nd} /{ }^{144} \mathrm{Nd}$ ratios were nearing homogenization at the third decimal in the second stage. The BFLs gave a mean $\varepsilon \mathrm{Nds}$ of 4.0 to -4.2 compared to $\varepsilon \mathrm{Nd}$ of -3.5 to -5.1 derived from the simulation. The simulation indicated that MSWD reaches 0.73 if complete isotopic homogenization occurred at $3.37 \mathrm{Ga}$ and the observed MSWD of 9.2 thus can be attributed to heterogeneities inherited from diverse protoliths homogenizing in the stage 2 not necessarily from a $3.37 \mathrm{Ga}$ event. Since the exact arrangement of the gneissic layers and their thicknesses of Moorbath et al (1997) study are unknown the simulation provides only limited information.

\section{Third stage of isochron translation provides meaningful ages and initial ratios}

A majority of BFLs gave mean ages close to (i.e. $\pm 25 \mathrm{Ma}$ ) the age of isotopic resetting for data from the third stage (Tables A4(a) \& (b)). Some mean $\mathrm{Rb}-\mathrm{Sr}$ ages identical to the resetting age had MSWD $>1$ and zero PoF for BFLs (Table A6). Those will be rejected as errorchrons during a study of natural samples, but the data can produce accurate ages using FGIR (later section). Mean $\mathrm{Rb}-\mathrm{Sr}$ and $\mathrm{Sm}-\mathrm{Nd}$ ages are identical to or within \pm 1 or $\pm 2 \mathrm{Ma}$ of the resetting age when MSWD $\leq 1$ and PoF is 1.0 at all $2 \sigma$ errors (Tables A4(a) \& (b), A5(a) \& (b)). However, the simulations suggest that such perfect isochrons requiring extensive isotopic homogenization could be rare in nature.

Tables A4(a) \& (b), A5(a) \& (b) summarize the ranges of (a) mean initial $\varepsilon N d$ and $\mathrm{I}_{\mathrm{Sr}}$ of a set of hundred BFLs calculated, (b) initial $\varepsilon N d$ and $\mathrm{I}_{\mathrm{Sr}}$ of local isotopic homogenization observed from the simulations. The observed initial $\varepsilon N d$ and $\mathrm{I}_{\mathrm{Sr}}$ indicate (i) the isotopic heterogeneity caused by local homogenization, (ii) the extent to which this heterogeneity is sampled by the hundred BFLs. The isotopic heterogeneity at the end of stage 1 is $10.5-11.5 \varepsilon \mathrm{Nd}$ units and range between $\sim 0.73-0.83$ in ${ }^{87} \mathrm{Sr} /{ }^{86} \mathrm{Sr}$ ratio. At a sampled step, the range of initial $\varepsilon N d$ and $\mathrm{I}_{\mathrm{Sr}}$ of the BFLs is narrow compared to the initial $\varepsilon \mathrm{Nd}$ and $\mathrm{I}_{\mathrm{Sr}}$ from simulations (Tables A4(a), (b)). This suggests that the initial $\varepsilon N d$ and $\mathrm{I}_{\mathrm{Sr}}$ of BFLs do not reflect the true extent of the heterogeneity. The calculated and the observed ranges of $\varepsilon \mathrm{Nd}$ and $\mathrm{I}_{\mathrm{Sr}}$ show only limited or partial overlap or sometimes no overlap at the sampled steps within the first and second stages depending on the arrangement of layers (Tables A4(a) \& (b)). As homogenization progresses and PoF of BFLs approach 1.0 within stage 3, the calculated initial $\varepsilon N d$ and $\mathrm{I}_{\mathrm{Sr}}$ lie within or totally overlap with the observed initial $\varepsilon N d$ and $\mathrm{I}_{\mathrm{Sr}}$ range of the isotopic heterogeneity. These observations have important implications on the inferences one makes based on the initial $\varepsilon \mathrm{Nd}$ and $\mathrm{I}_{\mathrm{Sr}}$ of BFLs of natural samples. Initial $\varepsilon \mathrm{Nd}$ and $\mathrm{I}_{\mathrm{Sr}}$ are used to infer the mantle source of protoliths and isotopic evolution of the mantle (DePaolo, 1981, McCulloch and Compston, 1981). Sometimes initial $\varepsilon N d$ and $\mathrm{I}_{\mathrm{Sr}}$ of granitic rocks are interpreted as mixtures between mantle 
derived melts and old continental crust, and as products of partial melting of old crust (DePaolo, 1980, 1981). The significance attached to initial $\varepsilon N d$ and $\mathrm{I}_{\mathrm{Sr}}$ of BFLs is valid only if their integrity as isochrons is proven. If the BFLs represent first or second stages of isochron translation, their initial $\varepsilon \mathrm{Nd}$ or $\mathrm{I}_{\mathrm{Sr}}$ may lie outside the true range of initial $\varepsilon N d$ or $\mathrm{I}_{\mathrm{Sr}}$ of that whole-rock volume (Tables A4(a), (b)). As noted above, the initial $\varepsilon \mathrm{Nd}$ or $\mathrm{I}_{\mathrm{Sr}}$ of a BFL is reliable only if a whole-rock volume has reached the third stage of isochron translation. But one cannot rule out a BFL showing MSWD $\leq 1$ and $\mathrm{PoF}=1.0$ within the second stage of isochron translation (ex. 146532-333333, Table A4(b)) particularly, if the time gap between the primary and resetting events is short.

FGIR to scrutinize a BFL for its integrity as an isochron and derivation of accurate metamorphic ages

In the current practice of the isochron method, isochrons are identified depending on how well the data fits a BFL. If a BFL shows MSWD 1 the line is often considered as an isochron. The simulations have indicated that BFLs with MSWD 1 may occur for data even from the stage 1 of isochron translation and only data from stage 3 give BFLs close to the resetting age. A FGIR characteristic of data from stage 3 is useful to identify whether a BFL represents data from stage 3 . In order to verify this, first the samples have to be arranged in the order they occurred in the field (Table A7) and their initial ratios have to be calculated at the mean age indicated by the BFL. The calculated initial ratios arranged in the field order of samples if define a FGIR, the data represents stage 3. The FGIR so obtained occurs at a range of ages older and younger than the age indicated by the BFL and one has to obtain their mean age. The data from simulations indicate that it is close to or represents the resetting age. The simulations also indicated that the initial ratios calculated at the age given by a BFL often do not define a FGIR even for data from stage 3 (Table A7). Then one has to recalculate the initial ratios at ages older or younger than the age given by the BFL. If the data truly represents stage 3 always there is a range of ages at which a FGIR exists and the mean age of that range is close to the resetting age. If such age range cannot be found the data do not represent stage 3. Table A7 is an example calculation from stage 3 data giving an errorchron $(2527 \pm 73 \mathrm{Ma}, \mathrm{MSWD}=556)$. At this age given by the BFL there is no FGIR, but one exists between $2481 \mathrm{Ma}$ and $2514 \mathrm{Ma}$. The mean age of that range $2497 \pm 16 \mathrm{Ma}$ is close to the resetting age of $2500 \mathrm{Ma}$ used in the simulation. This example shows that the data that would be rejected due to large MSWD is useful to give a reliable isotopic age if representing stage 3 . Tables A8 and A9 make comparisons between ages and initial ratios calculated from traditional BFLs and derived from use of FGIR for $\mathrm{Rb}-\mathrm{Sr}$ and $\mathrm{Sm}-\mathrm{Nd}$ data from stage 3 giving a wide range of MSWD for BFLs. Both tables indicate that information derived from use of FGIR is more accurate. In Table A10 the data from BFLs giving $2500 \mathrm{Ma}$ ages and other ages summarized in Table A6 have been used to find the age range of FGIR for $2500 \mathrm{Ma}$ BFLs and other BFLs in the manner described in Table A7. The age ranges at which a FGIR exists for $2500 \mathrm{Ma}$ BFLs and other BFLs are very similar. The mean age of those ranges is either identical or within 1-2 Ma from the resetting age used in the simulations. Use of FGIR is therefore a meaningful way to identify co-genetic samples and derive accurate isotopic ages. Its application requires systematic sampling that identifies accurate spatial relationships between the samples.

\section{Review of relationship between whole-rock isochrons and mineral isochrons}

The simulations reviewed the relationship between a whole-rock isochron and mineral isochrons of individual rocks. The former is often interpreted as a protolith age, and the latter as metamorphic ages envisaging isotopic redistribution at sample-scale (Wetherill et al., 1968, Nebel, 2015). In the simulations, isotopic redistribution occurs throughout all layers and local isotopic homogenization give perfect isochrons suggesting the resetting age from mid to end of stage 1 . Figure A7 shows a $3307 \pm 72$ Ma $(M S W D=1.13)$ BFL for twelve samples (two from each layer) from mid-Stage 1 of isochron translation in the Sm-Nd system of the arrangement 451623-333333. Four isochrons of local whole-rock isotopic homogenization in slices E, H, AD, AJ are also shown. Details of the BFL and twelve local whole-rock isochrons for all slices representing the twelve samples on the BFL are given in Table A11. Five out of the twelve slices give perfect isochrons with MSWD $<1$ and $\mathrm{PoF}=1$. The same twelve samples give a BFL of $3131 \pm 72 \mathrm{Ma}(\mathrm{MSWD}=1.4)$ at the end of stage 1 . Then all twelve slices give perfect 
isochrons and their mean age is very close to the mean age used in the simulation (Tables A1, A11). The two twelve-sample BFLs with MSWD 1 for all six layers mentioned above could be mistaken for isochrons. Neither those are representing the original 3500 Ma protolith isochron nor they give a FGIR since the samples represent stage 1 . The local whole-rock isotopic homogenization is an integral part of the process of resetting striving to isotopically homogenize all six layers in the arrangement by redistributing the isotopes throughout. It is logical to assume that minerals in the wholerocks defining the local isochrons are also homogenized to produce the same isochron. Thus, the simulations demonstrate that it is erroneous to assume (a) that mineral isochrons originate from isotopic redistribution confined to the scale of a whole-rock sample, (b) that the twelve-sample BFLs like the above are preserving a protolith age. Of course, those two BFLs partly preserve the protolith isotopic signature since the system is still within or at the end of stage 1. Even twelve-sample BFLs from layers representing stage 2 and local whole-rock isotopic homogenization would show a similar relationship. Thus, one can conclude that a mineral isochron is an indirectly sampled wholerock isochron of local isotopic homogenization. Field and Raheim (1979a, b) identified a mineral isochron and a whole-rock isochron suggesting the same age at their location 4, and nearby whole-rocks gave a 'meaningless' isochron suggesting partially reset protolith ages of rocks. Their observations are consistent with the above arguments.

\section{Isochron translation and Origin of Isotopic heterogeneities in the Crust and the Mantle}

Although the process of isotopic resetting is striving for isotopic homogenization in a wholerock volume, isochron translation leads it to an isotopic heterogeneity, which peaks at the end of stage 1 and gradually decays during stages 2 and 3 to achieve isotopic homogenization (Tables A4(a), (b)). Thus, isochron translation is a key to understand isotopic heterogeneities in the crust and the mantle. Assuming limited isotopic redistribution during metamorphism, Nd-model ages of gneisses are interpreted as crust formation ages (McCulloch and Wasserburg, 1980). But present-day isotopic compositions of the gneisses may reflect (a) isotopic differences of their protoliths inherited from the mantle, (b) initial $\mathrm{NNd}$ heterogeneities generated by isochron translation in the crust, (c) isotopic exchanges between the lower crust and the lithospheric mantle during high-grade metamorphism. An understanding of the structure of the lithospheric mantle and the length-scale of crust-mantle isotopic interaction would be necessary to assess the latter contribution. Although an influx of heat and $\mathrm{CO}_{2}$ from the mantle is often envisaged during granulite-facies metamorphism (Newton et al., 1980), isotopic interaction between the lower crust and the sub-crustal mantle is hitherto not investigated. Due to high geothermal and isotopic gradients prevailing such interaction cannot be ruled-out during amphibolite- to granulite-facies metamorphism. For example, BFLs with unusually high initial $\varepsilon N d$ were noted from high-grade orthogneisses of Sri Lanka (Perera, 2015). Detailed Sm-Nd and $\mathrm{Rb}-\mathrm{Sr}$ studies at individual localities have revealed isotopic disturbances across several metres during metamorphism and deformation (Perera and Kagami, 2011). Thus, a few lithologies in a quarry give nearly $1 \mathrm{Ga}$ range of model ages observed during regional sampling of one geological subdivision. All geological subdivisions of Sri Lanka give more than $2 \mathrm{Ga}$ range of $\mathrm{Nd}$ - and Sr-model ages, which are unlikely to represent true crust formation ages (Milisenda et al., 1988). These observations are attributed to isotopic heterogeneities introduced during isochron translation (Perera, 2015) due to repeated interaction with sub-crustal lithospheric mantle. Isochron translation generated a range of $11.5 \varepsilon \mathrm{Nd}$ units at the end of stage 1 during the simulations equivalent to $1.1 \mathrm{Ga}$ range of $\mathrm{T}_{\mathrm{CHUR}}$ model ages in crustal rocks with an average ${ }^{147} \mathrm{Sm} /{ }^{144} \mathrm{Nd}$ of $\sim 0.11$. Thus, factors (a), (b) and (c) mentioned above may have contributed to the wide range of model ages in Sri Lanka. Since model ages are being widely used to infer periods of crust formation in the Precambrian (Tomson et al., 2013, Dickin et al., 2010) there is an urgent necessity to understand isotopic heterogeneities introduced by isochron translation both in the crust and in the mantle.

An isotopic heterogeneity in the mantle is envisaged based on the diversity of isotopic composition of basalts. Zindler and Hart (1986) proposed linear two-component mixing between various mantle sources of basalts to explain this diversity. An isotopically layered sub-crustal lithosphere striving for isotopic equilibrium during periods of active tectonism could lead to the mantle heterogeneity during isochron translation if the sources of basalts are residing 
there. Hart (1988) too favours sub-continental mantle lithosphere as a possible source of basalts. Since layer arrangement is the prime factor controlling isochron translation one can fingerprint the structure of the sub-crustal lithospheric mantle leading to the envisaged isotopic heterogeneity. It involves an inverse problem. i.e. How did isochron translation produce the present-day isotopic composition of the sources of basalts over geological time? This has been successfully attempted in a parallel study (Perera, 2016), and the field relationships, layer thicknesses and parent isotopic compositions have been determined that would produce the observed (Zindler and Hart, 1986, Rollinson, 1998)) present-day $\mathrm{Pb}-\mathrm{Pb}, \mathrm{Pb}-\mathrm{Nd}$, $\mathrm{Pb}-\mathrm{Sr}$ and $\mathrm{Nd}-\mathrm{Sr}$ isotopic compositions in the basalt source regions. This approach to map the sub-crustal mantle lithosphere based on isochron translation will be presented elsewhere.

\section{CONCLUSIONS}

Computer simulations confirm translation of an isochron in an isochron diagram during isotopic resetting. The simulated whole-rock $\mathrm{Rb}-\mathrm{Sr}$ and Sm-Nd systems suggest that MSWD and PoF of BFLs for randomly collected data, (a) rely on too many factors, (b) improve towards $\leq 1$ and 1.0 , respectively, as isotopic homogenization progresses within stage 3 of isochron translation, (c) may give values $\leq 1$ for both the parameters for samples representing the stage 1 of isochron translation. Thus, MSWD and PoF of BFLs are unreliable parameters to declare an isochron unless and until one assures that the data collected represents stage 3 of isochron translation. Identifying a FGIR is a reliable way of assuring data from stage 3 to confirm cogenesis of samples, but that requires systematic sampling where spatial relationship between analyzed samples is accurately known. Although a perfect isochron shows MSWD $\leq 1$ and $\mathrm{PoF}=$ 1, data from stage 3 leading to BFLs with MSWD > 1 is useful to bracket the age of a geological event reliably. Isochron translation contributes to isotopic heterogeneities in the earth's crust and in the mantle. Isotopic systems show a maximum heterogeneity of initial ratios within stage 1 of isochron translation, thus, terrains subjected to mild late resetting events are likely to give wide ranges of model ages.

\section{ACKNOWLEDGMENTS}

Keshan Perera is thanked for assistance with drafting the figures. The two anonymous reviewers are thanked for their valuable comments. The two Co-Editors are thanked for their cooperation and speedy processing of the manuscript. Funding: Monthly Research Allowance to the author from University of Peradeniya provided financial support. Data and materials availability: Movies S1 and S2 and primary $\mathrm{Rb}-\mathrm{Sr}$ and $\mathrm{Sm}-\mathrm{Nd}$ data of modeled isochrons are available as supplementary material at the GSSL website given below. Data files generated at various stages of resetting cited in this article will be made available to interested readers. The software package used will not be available until all the important findings are published.

Supplementary material: www.gsslweb.org/

\section{REFERENCES}

Aftalion, M. and van Breemen, O. (1980). U-Pb zircon, monazite and $\mathrm{Rb} / \mathrm{Sr}$ whole rock systematics of granitic gneiss and psammitic to semi-pelitic host gneiss from Glenfinnan, northwestern Scotland. Contributions to Mineralogy and Petrology, 72: 87-98.

Bennett, V.C., Nutman, A.P. and McCulloch, M.T. (1993) $\mathrm{Nd}$ isotopic evidence for transient, highly depleted mantle reservoirs in the early history of the Earth. Earth and Planetary Science Letters, 119: 299-317.

Black, L.P., James, P.R. and Harley, S.L. (1983) The Geochronology, Structure and Metamorphism of Early Archaean Rocks at Fyfe Hills, Enderby Land, Antarctica. Precambrian Research, 21: 197-222.

Borg, L.E. Nyquist, L.E. Taylor, L.A. Wiesmann, H. and Shih, C.-Y. (1997) Constraints on Martian Differentiation Processes from $\mathrm{Rb}-\mathrm{Sr}$ and $\mathrm{Sm}-\mathrm{Nd}$ Isotopic Analyses of the Basaltic Shergottite QUE 94201. Geochimica et Cosmochimica Acta, 61: 4915-4931.

Boyet, M., Carlson, R.W. and Horan, M. (2010) Old Sm-Nd ages for cumulate eucrites and 
redetermination of the solar system initial ${ }^{146} \mathrm{Sm} /{ }^{144} \mathrm{Sm}$ ratio. Earth and Planetary Science Letters, 291: 172-181.

DePaolo, D.J. (1980) Sources of Continental Crust: Neodymium Isotope Evidence from the Sierra Nevada and Peninsular Ranges. Science, 209: 684-687.

DePaolo, D.J. (1981) Neodymium Isotopes in the Colorado Front Range and Crust Mantle evolution in the Proterozoic. Nature, 291: 193-196.

DePaolo, D.J. and Wasserburg, G.J. (1979) Sm$\mathrm{Nd}$ age of the Stillwater complex and the mantle evolution curve for neodymium. Geochimica et Cosmochimica Acta, 43: 999-1008.

DePaolo, D.J. and Getty, S.R. (1996) Models of isotopic exchange in reactive fluid-rock systems: Implications for geochronology in metamorphic rocks. Geochimica et Cosmochimica Acta, 60: 3933-3947.

Dickin, A.P. (1995) Radiogenic Isotope Geology, Cambridge University Press.

Dickin, A.P., McNutt, R.H., Martin, C. and Guo, A. (2010) The extent of juvenile crust in the Grenville Province: $\mathrm{Nd}$ isotope evidence. Geological Society of America Bulletin, 122: 870-883.

Faure, G. (1966) Isotope Geology, $2^{\text {nd }}$ Edition, Wiley, New York.

Field, D. and Raheim, A. (1979a) Rb-Sr total rock isotope studies on Precambrian charnockitic gneisses from southern Norway: evidence for isochron resetting during a low-grade metamorphicdeformational event. Earth and Planetary Science Letters, 45: 32-44.

Field, D. and Raheim, A. (1979b) A geologically meaningless $\mathrm{Rb}-\mathrm{Sr}$ total rock isochron. Nature, 282: 497-499.

Gaffney, A.M. and Borg, L.E. (2014) A young solidification age for the lunar magma ocean. Geochimica et Cosmochimica Acta, 140: 227-240.

Hahn, O., Strassman, F., Mattauch, J. and Ewald, H. (1943) Geologische Altersbestimmungen mit der strontiummethode. Chemiker Zeitung, 67: 55-56.

Hart, S.R. (1988) Heterogeneous mantle domains: signatures, genesis and mixing chronologies. Earth and Planetary Science Letters, 90: 273-296.

Ludwig, K. R. (2008) User's Manual for ISOPLOT 3.6, Berkeley Geochronology Centre Special Publication, No. 4, 77p.
Lugmair, G.W., Scheinin, N.B. and Marti, K. (1975) Search for extinct 146Sm 1. The isotopic abundance of ${ }^{142} \mathrm{Nd}$ in the Juvinas meteorite. Earth and Planetary Science Letters, 27: 79-84.

McCulloch, M.T. and Compston, W. (1981) Sm$\mathrm{Nd}$ age of Kambalda and Kanowna greenstones and heterogeneity in the Archaean mantle. Nature, 294: 322-327.

McCulloch, M.T. and Wasserburg, J.G. (1980) $\mathrm{Sm}-\mathrm{Nd}$ and $\mathrm{Rb}-\mathrm{Sr}$ geochronology of crust formation. Science, 200: 1003-1011.

McIntyre, G.A., Brooks, C., Compston, W. and Turek, A. (1966) The statistical assessment of $\mathrm{Rb}-\mathrm{Sr}$ isochrons. Journal of Geophysical Research, 71: 5459-5468.

Milisenda, C.C., Liew, T.C., Hofmann, A.W. and Kröner, A. (1988) Isotopic Mapping of Age Provinces in Precambrian High-Grade Terrains: Sri Lanka. Journal of Geology, 96: 608-615.

Moorbath, S. (1975a) Evolution of Precambrian crust from strontium isotopic evidence. Nature, 254: 395-398.

Moorbath, S. (1975b) The geological significance of Early Precambrian rocks. Proceedings of the Geological Association, 86 (3): 259-279.

Moorbath, S. (1977) Ages, Isotopes and Evolution of Precambrian Continental Crust. Chemical Geology, 20: 151-187.

Moorbath, S., Whitehouse, M.J. and Kamber, B.S. (1997) Extreme Nd-isotope heterogeneity in the early Archaean - fact or fiction? Case histories from northern Canada and West Greenland. Chemical Geology, 135: 213-231.

Nebel, O. (2015) Rb-Sr dating. In: W.J. Rink, and J. W. Thompson, (Editors) Encyclopedia of Scientific Dating Methods. Springer, 978 pp.

Newton, R.C., Windley, B.F. and Smith, J.V. (1980) Carbonic metamorphism, granulites and crustal growth. Nature, 288: 45-50.

Nicolaysen, L.O. (1961) Graphic interpretation of discordant age measurements on metamorphic rocks. Annals of the New York Academy of Sciences, 91: 198-206.

Papanastassiou, D.A. and Wasserburg, G.J. (1969) Initial strontium isotope abundances and the resolution of small time differences in the formation of planetary objects. Earth and Planetary Science Letters, 5: 361-376.

Perera, L.R.K. (2015) Isochron Translation, Mantle Mapping and Sri Lankan Model 
ages. Ananda Coomaraswamy Memorial Oration 2014, Journal of the Geological Society of Sri Lanka, 17: 1-10.

Perera, L.R.K. (2016) Isochron Translation and Mapping Mantle Layering. Proc. $32^{\text {nd }}$ Annual Technical Sessions of the Geological Society of Sri Lanka (Abstract) p.3.

Perera, L.R.K. and Kagami, H. (2011) Centimetre- and Metre-scale $\mathrm{Nd}$ and $\mathrm{Sr}$ Isotopic Homogenization in Kadugannawa Complex, Sri Lanka. Journal of the Geological Society of Sri Lanka, 14: 129141.

Rink, W.J. and Thompson, J.W. (ed.) (2015) Encyclopedia of Scientific Dating Methods. Springer, 978 pp.

Rollinson, H. (1998) Using Geochemical Data: evaluation, presentation, interpretation. Longman $352 \mathrm{pp}$.

Shirey, S.B. and Hanson, G.N. (1986) Mantle Heterogeneity and crustal recycling in Archaean granite-greenstone belts: evidence from $\mathrm{Nd}$ isotopes and trace elements in the Rainy Lake area, Superior Province, Ontario, Canada. Geochimica et Cosmochimica Acta, 50: 2631-2651.
Snyder, G.A., Lee, D-C., Taylor, L.A., Halliday, A.N. and Jerde, E.A. (1994) Evolution of the upper mantle of the Earth's Moon: Neodymium and strontium isotopic constraints from high-Ti mare basalts. Geochimica et Cosmochimica Acta, 58: 4795-4808.

Tomson, J.K., Bhaskar Rao, Y.J., Vijaya Kumar, T. and Choudhary, A.K. (2013) Geochemistry and neodymium model ages of Precambrian charnockites, Southern Granulite Terrain, India: Constraints on terrain assembly. Precambrian Research, 227: 295-315.

Wetherill, G.W., Davis, G.L. and Lee-Hu, C. (1968) $\mathrm{Rb}-\mathrm{Sr}$ measurements on wholerocks and separated minerals from the Baltimore gneiss, Maryland. Bulletin of the Geological Society of America, 79: 757762.

York, D. (1969) Least-squares fitting of a straight line with correlated errors. Earth and Planetary Science Letters, 5: 320-324.

Zindler, A. and Hart, S. (1986) Chemical Geodynamics. Annual Reviews in Earth and Planetary Sciences, 14: 493-571. 


\title{
APPENDIX
}

\section{ISOCHRON TRANSLATION AND A GEOLOGICAL CRITERION TO DECLARE AN ISOCHRON}

\author{
L. R. K. PERERA \\ Department of Geology, University of Peradeniya, Peradeniya, Sri Lanka.
}

\section{METHODS}

\section{MAKE-UP OF A SINGLE LAYERED VOLUME OF WHOLE-ROCKS FOR SIMULATIONS}

The starting point of all computer simulations is an initial whole-rock $\mathrm{Rb}-\mathrm{Sr}$, Sm-Nd isochron among several (six or eighteen) lithological layers represented by more than thousand hypothetical samples, contiguous in threedimensional space. The layers in a given sequence are of equal or unequal thickness and are represented by hundreds of hypothetical cube-shaped samples (Fig. A1). Computer software arranges the layers of desired thickness, in any order of choice to make-up a layered sequence. Fig. A1 depicts a column of six-layers of equal thickness. There, one layer is represented by a large coloured cube having six small cubes along its length, thus, containing 216 small cubes in total, lying on six slices parallel to layer boundaries, each slice containing 36 small cubes. The six-layer column contains 1296 small cubes. Each layer parallel slice has been identified by a label from A to AJ to facilitate understanding of information in the figures. Long length-scale isotopic resetting was simulated using an eighteen-layer column containing 3888 small cubes lying on 108 layer parallel slices. The labels of slices of Fig. A1 continue in the 108 slices from AK to AZ, BA to $\mathrm{BZ}, \mathrm{CA}$ to $\mathrm{CZ}$ and $\mathrm{DA}$ to $\mathrm{DD}$. In the relevant diagrams and tables in later sections, position of slabs and coordinates of the small cube samples in 3D space are referred to using these slab labels. Random sampling of the six- or eighteenlayer columns of rocks as in the present-day, with a desired number of samples per layer, was carried-out at different stages of isotopic resetting in order to understand how the statistical parameters like Mean Square of Weighted Deviates (MSWD) and Probability (PoF) of Best-Fit Lines (BFLs) to isotopic data on an isochron diagram vary with progressive resetting and with the number of sets of samples collected at a given step of resetting.

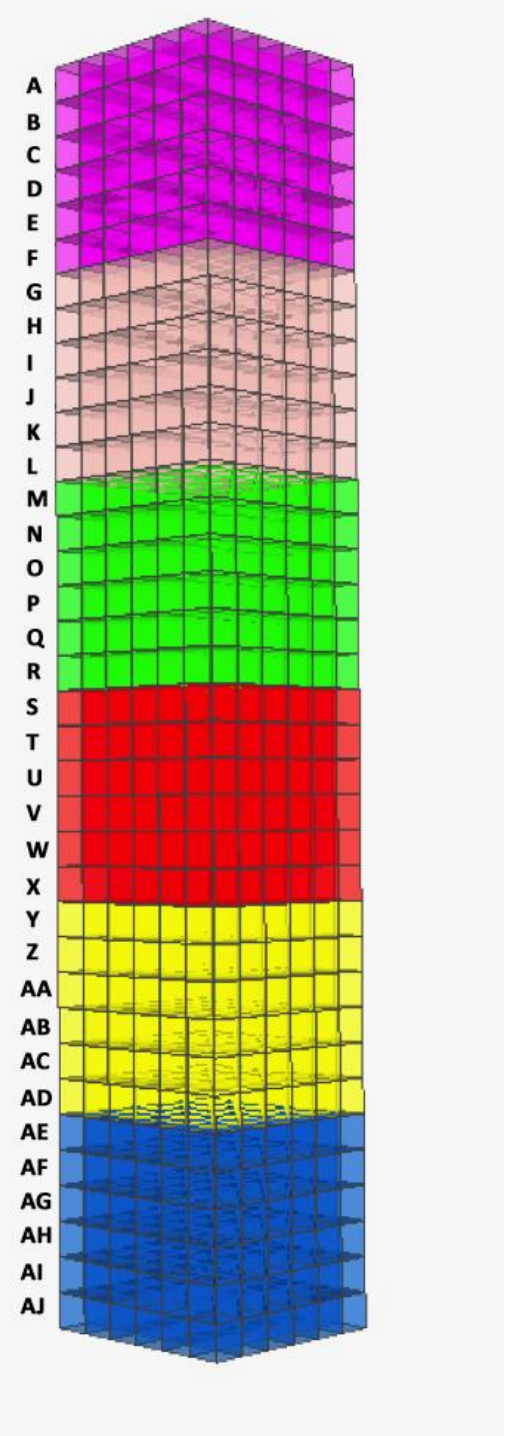

Fig. A1. A column of 1296 cube-shaped wholerock samples, which is representing a six-layer arrangement. The layers are of equal thickness, each one of them represented by a coloured large cube consisting of 216 samples. A large cube has six small cubes along its length, thus, each layer contains six layer-parallel slices, each containing 36 samples. All 36 slices in the column are labeled from A to AJ. 


\section{COMPUTER SOFTWARE MADE USE IN THE SIMULATIONS}

The author developed the software package used in the simulations. It is designed to facilitate, (a) changes of layer arrangement, layer thickness, layer isotopic composition, protolith ages and length-scale of isotopic resetting to understand their influence on observations at the time of isotopic resetting and in the present-day, (b) random sampling of a desired number of samples from a layer, as in the present-day and as at the time of isotopic resetting, at any desired stage of the process for isotopic data analysis. Simulations of this kind mimicking nature are not known. A simulation based on calculation of progress of one-dimensional isotopic exchange where a fluid facilitates the process has been noted (DePaolo and Getty, 1996).

\section{SAMPLING PRESENT-DAY ISOTOPIC DATA FROM THE SIMULATIONS FOR STATISTICAL ANALYSIS}

Present-day isotopic data from the simulations were sampled for statistical analysis from all three stages of isochron translation. Always one hundred (100) sets of data were collected at a chosen step of isotopic resetting. For a given set, mostly two samples were randomly collected from a layer, both in six-layer and eighteenlayer arrangements. One six-layer arrangement was sampled at one step to understand how the MSWD and PoF of BFLs depend on the number of samples collected from a layer. Marginal layers and inner layers showing short-lived homogenization of all samples, within stage 2 and before reaching the CIT, were also sampled from all layer arrangements studied. Samples from layer parallel slabs were also collected towards the end of stage 1 to show the local isotopic homogenization achieved and the relationship between local isotopic homogenization and BFLs for whole-rock samples from individual layers.

\section{REGRESSION ANALYSIS OF COLLECTED ISOTOPIC DATA}

Linear regression analysis of sampled data was carried-out using the software package ISOPLOT (Ludwig, 2008). The data from simulations do not have analytical errors, but $2 \sigma$ percentage errors are a necessity to perform the calculations. Thus, $2 \sigma$ errors of $0.5 \%$ and $0.1 \%$ were assumed on ${ }^{87} \mathrm{Rb} /{ }^{86} \mathrm{Sr}$ and ${ }^{147} \mathrm{Sm} /{ }^{144} \mathrm{Nd}$ ratios, respectively. Three different percentage
$2 \sigma$ errors $(0.01 \%, 0.0044 \%, 0.0025 \%)$ were used on ${ }^{87} \mathrm{Sr} /{ }^{86} \mathrm{Sr}$ and ${ }^{143} \mathrm{Nd} /{ }^{144} \mathrm{Nd}$ ratios to understand their influence on the result. Analytical errors on both daughter and parent ratios of natural samples vary between laboratories and most $2 \sigma$ errors on daughter ratios are in the range $0.0044 \%-0.0025 \%$.

\section{ISOTOPIC RATIOS OF THE SAMPLES USED IN THE SIMULATIONS}

In the choice of present-day parent isotopic ratios of samples used in the simulations care was taken to be consistent with natural samples. The range of parent ${ }^{87} \mathrm{Rb} /{ }^{86} \mathrm{Sr}$ and ${ }^{147} \mathrm{Sm} /{ }^{144} \mathrm{Nd}$ ratios observed in Sri Lankan high-grade gneisses was used as a guide (Milisenda et al 1988, Perera and Kagami, 2011). Protoliths of layers assumed to have been derived from the Uniform Reservoir (UR) or Chondritic Uniform Reservoir (CHUR) 3500 Ma ago were subject to resetting mostly at $2500 \mathrm{Ma}$ and also at $3000 \mathrm{Ma}$ to allow sufficient change in daughter ratios, particularly ${ }^{143} \mathrm{Nd} /{ }^{144} \mathrm{Nd}$. Awareness on changes in ${ }^{87} \mathrm{Sr} /{ }^{86} \mathrm{Sr}$ and ${ }^{143} \mathrm{Nd} /{ }^{144} \mathrm{Nd}$ produced by decay within a given time frame is important to understand the scatter of data on an isochron diagram for disturbed isotopic systems, thus, the MSWD of BFLs. Each layer is having a distinct range of computer generated parent ratios that are randomly distributed in space. The ranges of parent ratios of different layers show various degrees of overlapping (or no overlapping). The degree of overlapping between the parent ratios is purely hypothetical. Present-day $\mathrm{Rb}-\mathrm{Sr}$ and Sm-Nd data of the $3500 \mathrm{Ma}$ isochrons used in the simulations are given in the Supplementary Table Protolith Data.

\section{NOTATION USED TO IDENTIFY A LAYER ARRANGEMENT}

In the notation used to describe the field relationship of a six-layer arrangement an integer from 1 to 6 was assigned to identify each layer according to the highest parent isotopic ratio a layer contains with respect to the other layers. Thus, number 6 was assigned to the layer containing the highest parent ratio irrespective of the lowest ratio it contains, and number 1 to the layer where its highest parent ratio is the lowest among the layers. Thus, 325146 designate a six-layer sequence where the layer with the highest parent ratio represents one end of the sequence. Similarly, an integer was assigned to each layer to describe its thickness 
compared to the layer with the smallest thickness (two cube-lets wide $=1$ ) the software package used. A large cube with six cube-lets along a side in Fig. A1 was assigned integer 3 . Thus, a given simulation is identified by two sets of numbers, the first set describing the arrangement of the layers in the field, and the second set, the thicknesses of those layers in the same order (Ex. 241635-333333, 425163342561)(See Figs. 1, 3, 4 of main text). To invoke a long length-scale of homogenization a few eighteen-layer sequences were studied. Since only six-ranges of parent ratios were used an eighteen-layer arrangement has the six numbers repeating in space in a desired sequence.

\section{ISOTOPIC RESETTING OCCURRING IN A SINGLE LAYERED VOLUME}

Isotopic exchange between the samples in three mutually perpendicular directions was assumed to be proportional to the daughter isotopic gradients that exist among those. The software eliminates a fraction of this gradient between a sample and its six neighbouring samples in one step and achieves isotopic homogenization among the samples in hundreds or thousands of steps, depending on whether fast or slow rates of isotopic exchange are used. To save computer time, fast rates of isotopic exchange were used during the simulations. The 362514-333333 was reset at five (05) different rates to note that the rates of exchange applied have no significant influence on the inferences made on the resetting process. In nature, fluid-bearing and fluid-absent lithologies could be interlayered and complete homogenization of a whole-rock volume will be controlled by the very slow rate of isotopic exchange in fluid-absent layers. In the simulations, only one chosen rate of isotopic exchange was used for all layers. Extremely slow rates of isotopic exchange demonstrate isochron translation vividly. Figure 2 in the main text has been constructed using data from the slowest rate used to get details of development of the field gradient of initial ratios (FGIR) within different layers. Figure A2 is a compilation of all data given as separate panels in Fig. 2 to show how the FGIRs within different layers coalesce to produce the FGIR between all the layers at the Culmination of Isochron Translation (CIT)(later section). As resetting was progressing, isotopic composition of the samples was monitored on isochron diagrams as at the time of resetting and present-day, simultaneously. Since data of all samples of a given simulation are plotted, only layer arrangements having equal layer thickness are shown to simplify the isochron diagrams. Simulations were performed until isotopic homogenization occurred at the sixth decimal place. Also all layer arrangements represent closed isotopic systems.

\section{CHANGE OF LENGTH-SCALE OF ISOTOPIC HOMOGENIZATION}

As mentioned above six-layer and eighteenlayer arrangements were used in the simulations to vary the length-scale of isotopic homogenization. In both arrangements thickness of the layers was uniform and the ranges of parent ratios of the layers are similar. Irrespective of the number of layers, their thicknesses, and protolith ages, all whole-rock volumes subject to isotopic resetting had layerparallel volumes of local isotopic homogenization throughout the process. Compared to a six-layer arrangement eighteenlayers takes very large number of steps to reach a given milestone in the process of isotopic resetting (ex. Reaching the Culmination of Isochron Translation (CIT)). Thus, a fast rate of isotopic exchange was used in an eighteen-layer arrangement. In six-layer arrangements, use of six different layer thicknesses also increased the length-scale, thus, the number steps required to achieve a desired level of homogenization.

\section{RESULTS OF REGRESSION ANALYSIS OF DATA FROM SIMULATIONS}

\section{ISOCHRONS OF LOCAL ISOTOPIC HOMOGENIZATION}

Table A1 gives BFLs of local isotopic homogenization in twelve (12) layer parallel slices at the end of stage 1 of the Sm-Nd system of the arrangement 451623-333333. Two slices from each layer was sampled, each containing 36 samples. The slices give perfect isochrons $(\mathrm{MSWD} \leq 1, \mathrm{PoF}=1)$ at all $2 \sigma$ errors used, with a mean age \pm 27 Ma from the true resetting age of $2500 \mathrm{Ma}$. The 12-sample BFL (MSWD = 1.4) containing 02 samples from each layer gives an older age that could be mistaken for an isochron. 


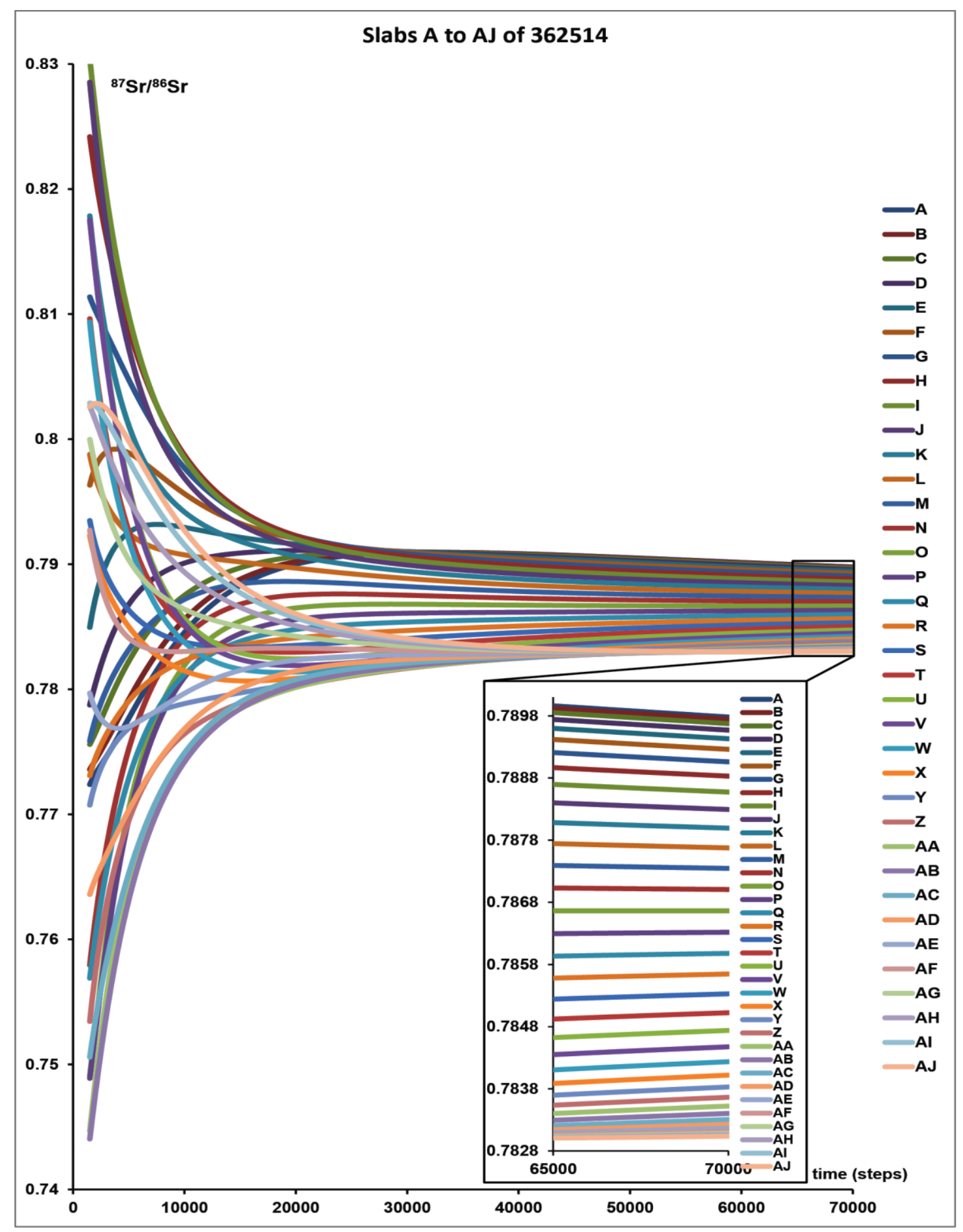

Fig. A2. Variation of initial ${ }^{87} \mathrm{Sr} /{ }^{86} \mathrm{Sr}$ ratios of slabs A to AJ of the six-layer arrangement 362514 leading to FGIR at the end of Stage 2 of isochron translation (see inset for the FGIR). This point in the resetting process is described in the text as the Culmination of Isochron Translation (CIT) since the relative positions of layers and their slabs remain fixed in the isochron diagram beyond that point. All data in Figs. 2(a)-(f) are used here. Also see Fig. A4(i) (451623-333333), and Fig. 1(e) (426513-333333) in the main text. 


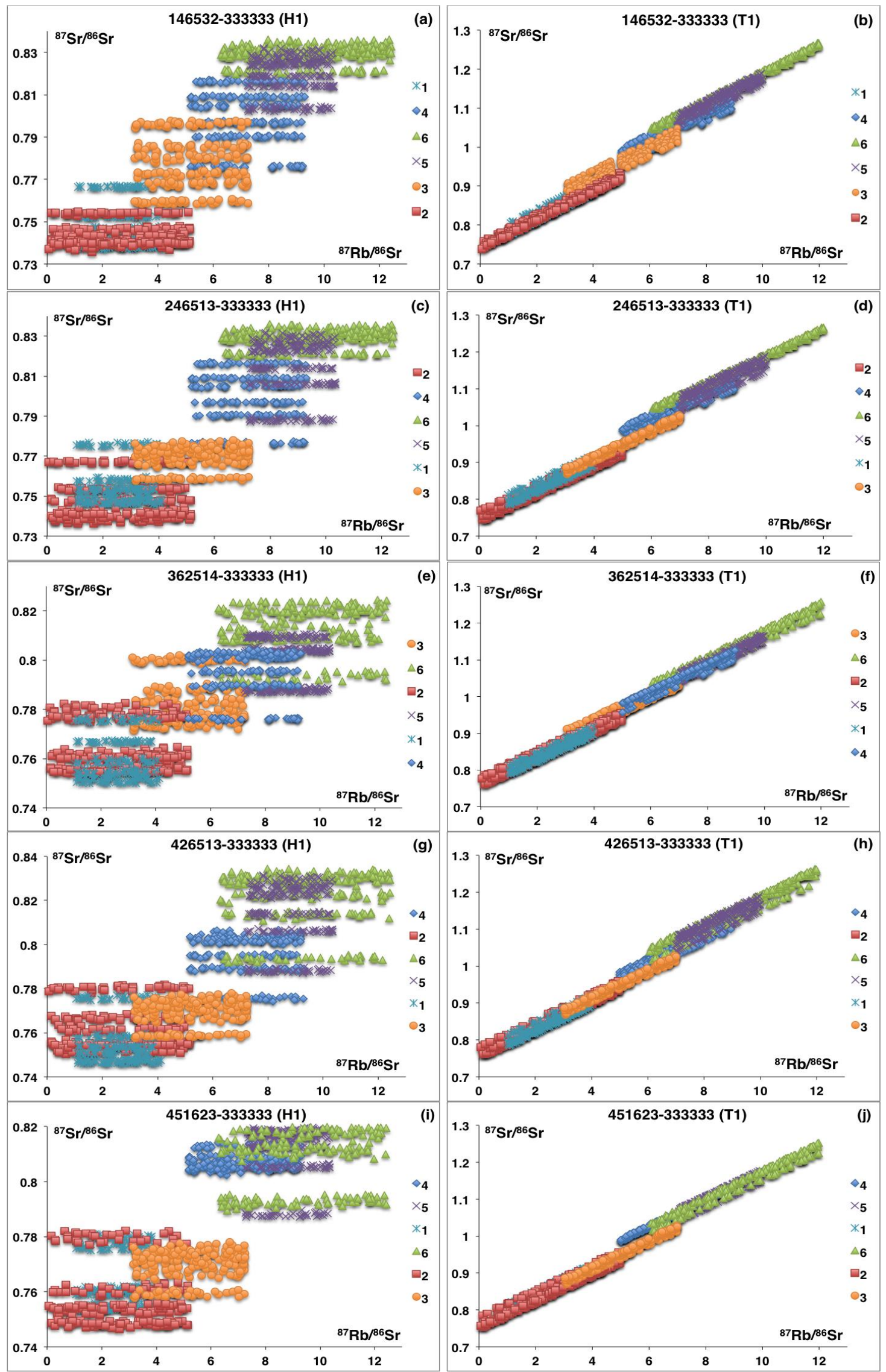

Fig. A3. Five arrangements of the same six layers after 10 steps of resetting at the end of Stage 1. Isochron translation in isochron diagrams at the time of resetting (left) and present-day (right). A 3500 Ma isochron is being reset at $2500 \mathrm{Ma}$. Note the differences arising from diverse layer arrangements. Also see Fig. A4. 


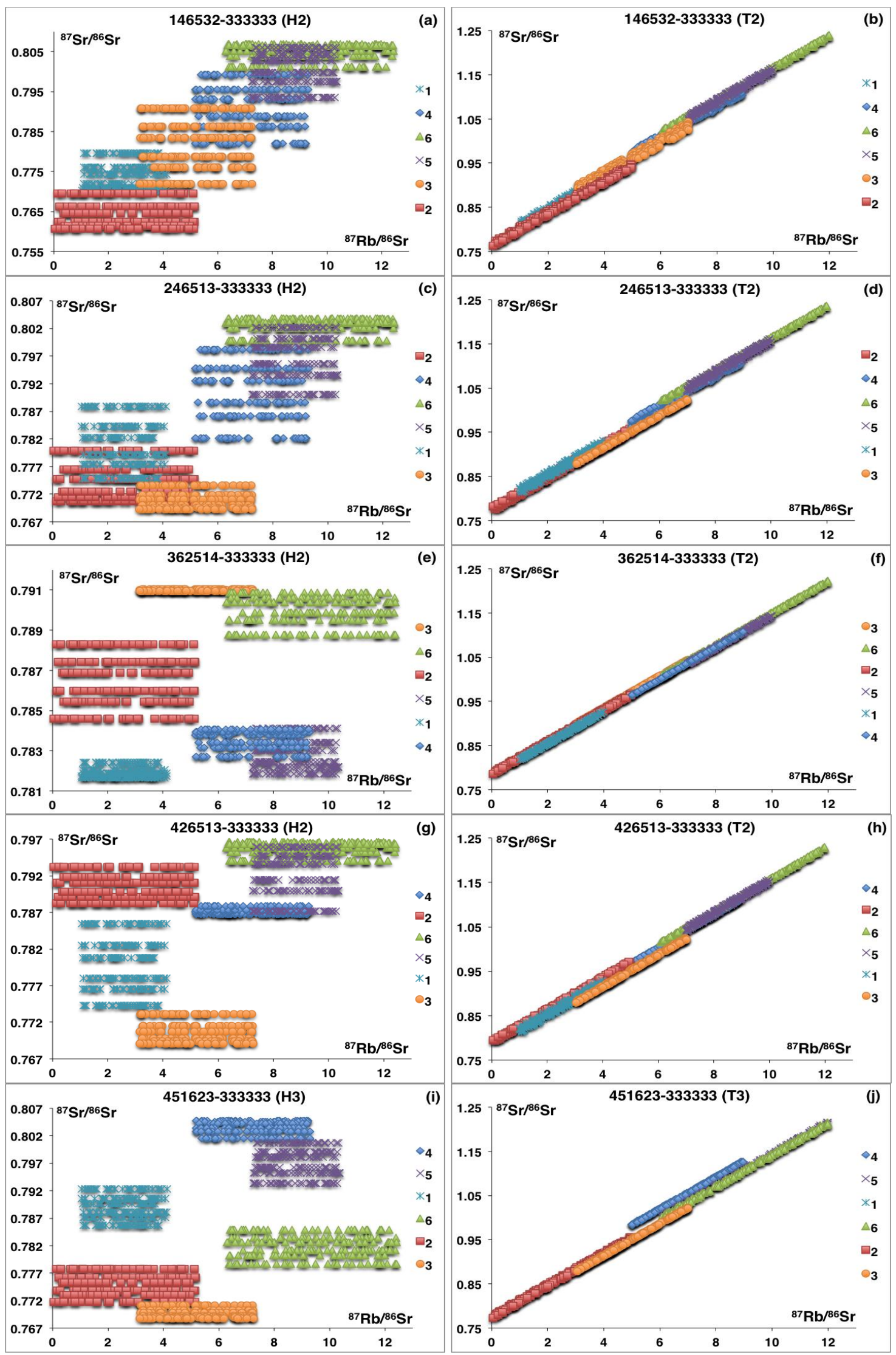

Fig. A4. Isochron translation after 120 steps in layer arrangements of Fig. A3, at the time of resetting (left) and present-day (right). All except 451623-333333 in Fig. A4(i) represent Stage 2 as evident from overlapping initial ratios of local homogenization within layers. 451623 reached Stage 3 after 70 steps and define a FGIR although the initial ratios differ even at first decimal. Note the completely homogenized Layer 3 of 362514-333333 in (e) and Movie S1. 
Table A1. Local isotopic homogenization in twelve slices at the end of stage 1. Each 36-sample slice in layer arrangement 451623-333333 defines a perfect isochron with MSWD $<1$ and PoF $=1$.

\begin{tabular}{|c|c|c|c|c|c|c|}
\hline Layer & $\begin{array}{l}\text { Slice } \\
\text { Label }\end{array}$ & Age (Ma)* & $\begin{array}{l}\text { Initial } \\
\text { eNd }(\mathbf{T}) *\end{array}$ & $\begin{array}{r}\text { MSWD (PoF) } \\
2 \sigma=0.01 \%\end{array}$ & $\begin{array}{r}\text { MSWD (PoF) } \\
2 \sigma=0.0044 \%\end{array}$ & $\begin{array}{l}\text { MSWD (PoF) } \\
2 \sigma=0.0025 \%\end{array}$ \\
\hline \multirow[t]{2}{*}{4} & $\mathrm{~B}$ & $2511 \pm 190$ & $-8.27 \pm 3.14$ & $0.022(1)$ & $0.115(1)$ & $0.35(1)$ \\
\hline & $\mathrm{E}$ & $2521 \pm 170$ & $-7.62 \pm 2.94$ & $0.016(1)$ & 0.084 (1) & $0.26(1)$ \\
\hline \multirow[t]{2}{*}{5} & G & $2505 \pm 210$ & $-6.85 \pm 4.12$ & $0.021(1)$ & 0.107 (1) & $0.32(1)$ \\
\hline & $\mathrm{H}$ & $2513 \pm 220$ & $-6.45 \pm 4.32$ & $0.013(1)$ & $0.066(1)$ & $0.2(1)$ \\
\hline \multirow[t]{2}{*}{1} & $\mathrm{O}$ & $2502 \pm 190$ & $-13.41 \pm 1.96$ & $0.00021(1)$ & $0.0011(1)$ & $0.0034(1)$ \\
\hline & $\mathrm{Q}$ & $2498 \pm 220$ & $-12.53 \pm 2.36$ & $0.0022(1)$ & $0.0115(1)$ & 0.035 \\
\hline \multirow[t]{2}{*}{6} & $\mathrm{~T}$ & $2511 \pm 210$ & $-6.3 \pm 2.53$ & $0.0026(1)$ & 0.013 & $0.04(1)$ \\
\hline & $\mathrm{U}$ & $2504 \pm 230$ & $-5.7 \pm 5.1$ & $0.0012(1)$ & $0.0063(1)$ & $0.019(1)$ \\
\hline \multirow[t]{2}{*}{2} & $\mathrm{Z}$ & $2519 \pm 200$ & $-10.42 \pm 2.55$ & $0.0018(1)$ & $0.0095(1)$ & $0.029(1)$ \\
\hline & $\mathrm{AD}$ & $2517 \pm 230$ & $-11.65 \pm 2.94$ & 0.015 & 0.078 & $0.24(1)$ \\
\hline \multirow[t]{2}{*}{3} & $\mathrm{AF}$ & $2527 \pm 110$ & $-10.66 \pm 1.69$ & $0.015(1)$ & 0.074 (1) & $0.23(1)$ \\
\hline & AJ & $2513 \pm 120$ & $-10.2 \pm 1.87$ & 0.019 (1) & $0.097(1)$ & $0.29(1)$ \\
\hline $\begin{array}{l}\text { Whole-rock } \\
\text { BFL } \\
\text { (12 samples) }\end{array}$ & & $3131 \pm 72$ & $-3.38 \pm 1.22$ & $1.4(0.17)$ & $7.2(0)$ & $22(0)$ \\
\hline
\end{tabular}

*Age and Initial eNd (T) given at $2 \sigma=0.01 \%$ of ${ }^{143} \mathrm{Nd} /{ }^{144} \mathrm{Nd}$ and $0.1 \%$ of ${ }^{147} \mathrm{Sm} /{ }^{144} \mathrm{Nd}$.

Table A2. 'Flash' Isochrons from the Rb-Sr and Sm-Nd systems from six-layer arrangements. All give $M S W D<1$, all except one give PoF $=1$, thus, are perfect isochrons.

\begin{tabular}{|c|c|c|c|c|c|c|c|}
\hline \multicolumn{8}{|c|}{ Rb-Sr system } \\
\hline \multicolumn{2}{|c|}{$\begin{array}{l}\text { Layer Relation } \\
\text { (Reset step) }\end{array}$} & $\begin{array}{c}\text { Layer } \\
6\end{array}$ & $\begin{array}{l}\text { Age (Ma) } \\
2501 \pm 4\end{array}$ & $\begin{array}{l}\mathbf{I}_{\text {Sr from }} \\
\text { BFL } \\
0.79042 \pm 51\end{array}$ & $\begin{array}{l}\begin{array}{l}\text { MSWD } \\
\text { (PoF) } \\
\text { 20=0.01\% } \\
0.052(1)\end{array}\end{array}$ & \begin{aligned} \multicolumn{1}{l}{$\begin{array}{l}\text { MSWD } \\
\text { (PoF) }\end{array}$} \\
$\begin{array}{r}\mathbf{2 \sigma = 0 . 0 0 4 4 \%} \\
0.052(1)\end{array}\end{aligned}$ & 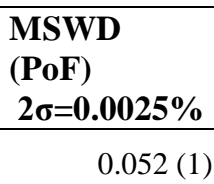 \\
\hline 146532 & $\begin{array}{l}(325) \\
(500) \\
(550)\end{array}$ & $\begin{array}{l}6 \\
4 \\
1\end{array}$ & $\begin{array}{l}2501 \pm 4 \\
2500 \pm 5 \\
2500 \pm 5\end{array}$ & $\begin{array}{l}0.79042 \pm 51 \\
0.78794 \pm 47 \\
0.78774 \pm 47\end{array}$ & $\begin{array}{r}0.052(1) \\
0.0047(1) \\
0.0065(1)\end{array}$ & $\begin{array}{r}0.052(1) \\
0.0048(1) \\
0.0065(1)\end{array}$ & $\begin{array}{r}0.052(1) \\
0.0048(1) \\
0.0065(1)\end{array}$ \\
\hline 246513 & $\begin{array}{l}(552) \\
(600)\end{array}$ & $\begin{array}{l}4 \\
2\end{array}$ & $\begin{array}{l}2500 \pm 5 \\
2500 \pm 1\end{array}$ & $\begin{array}{l}0.78714 \pm 47 \\
0.78708 \pm 02\end{array}$ & $\begin{array}{l}0.00046(1) \\
0.00061(1)\end{array}$ & $\begin{array}{r}0.00046(1) \\
0.0013(1)\end{array}$ & $\begin{array}{r}0.00046(1) \\
0.0018(1)\end{array}$ \\
\hline 362514 & $\begin{array}{l}(120) \\
(180) \\
(225)\end{array}$ & $\begin{array}{l}3 \\
1 \\
4\end{array}$ & $\begin{array}{l}2500 \pm 3 \\
2500 \pm 2 \\
2500 \pm 5\end{array}$ & $\begin{array}{l}0.79097 \pm 23 \\
0.78277 \pm 07 \\
0.78299 \pm 47\end{array}$ & $\begin{array}{r}0.0049(1) \\
0.13(1) \\
0.00037(1)\end{array}$ & $\begin{array}{r}0.005(1) \\
0.14(1) \\
0.00037(1)\end{array}$ & $\begin{array}{r}0.005(1) \\
0.14(1) \\
0.00037(1)\end{array}$ \\
\hline 426513 & $\begin{array}{l}(300) \\
(350)\end{array}$ & $\begin{array}{l}2 \\
4\end{array}$ & $\begin{array}{l}2500 \pm 1 \\
2500 \pm 5\end{array}$ & $\begin{array}{l}0.79004 \pm 02 \\
0.78977 \pm 47\end{array}$ & $\begin{array}{r}0.33(1) \\
0.0013(1)\end{array}$ & $\begin{array}{r}0.67(1) \\
0.0013(1)\end{array}$ & $\begin{array}{r}0.95(0.69) \\
0.0013(1)\end{array}$ \\
\hline 451623 & $\begin{array}{l}(40) \\
(60)\end{array}$ & $\begin{array}{l}4 \\
3\end{array}$ & $\begin{array}{l}2500 \pm 5 \\
2499 \pm 3\end{array}$ & $\begin{array}{l}0.80804 \pm 47 \\
0.76746 \pm 23\end{array}$ & $\begin{array}{l}0.27(1) \\
0.21(1)\end{array}$ & $\begin{array}{l}0.27(1) \\
0.21(1)\end{array}$ & $\begin{array}{l}0.27(1) \\
0.21(1)\end{array}$ \\
\hline \multicolumn{8}{|c|}{ Sm-Nd system } \\
\hline $\begin{array}{l}\text { Layer I } \\
\text { (Reset }\end{array}$ & $\begin{array}{l}\text { elation } \\
\text { ep) }\end{array}$ & Layer & Age (Ma) & $\begin{array}{c}\text { ENd from } \\
\text { BFL }\end{array}$ & $\begin{array}{c}\text { MSWD } \\
\text { (PoF) } \\
2 \sigma=0.01 \%\end{array}$ & $\begin{array}{c}\text { MSWD } \\
\text { (PoF) } \\
\text { 2б=0.0044\% }\end{array}$ & $\begin{array}{l}\text { MSWD } \\
(\text { PoF) } \\
2 \sigma=0.0025 \%\end{array}$ \\
\hline 146532 & $\begin{array}{l}(890) \\
(950)\end{array}$ & $\begin{array}{l}3 \\
2\end{array}$ & $\begin{array}{l}2500 \pm 52 \\
2500 \pm 83\end{array}$ & $\begin{array}{l}-9.4 \pm 0.8 \\
-9.4 \pm 1.1\end{array}$ & $\begin{array}{l}0(1) \\
0(1)\end{array}$ & $\begin{array}{l}0(1) \\
0(1)\end{array}$ & $\begin{array}{l}0(1) \\
0(1)\end{array}$ \\
\hline 246513 & $\begin{array}{l}(440) \\
(442)\end{array}$ & $\begin{array}{l}2 \\
4\end{array}$ & $\begin{array}{l}2500 \pm 83 \\
2499 \pm 71\end{array}$ & $\begin{array}{l}-9.1 \pm 1.1 \\
-9.1 \pm 1.2\end{array}$ & $\begin{array}{r}0(1) \\
0.000116(1)\end{array}$ & $\begin{array}{r}0.00038(1) \\
0.0006(1)\end{array}$ & $\begin{array}{r}0.00117(1) \\
0.0018(1)\end{array}$ \\
\hline 362514 & $\begin{array}{l}(135) \\
(140)\end{array}$ & $\begin{array}{l}4 \\
3\end{array}$ & $\begin{array}{l}2501 \pm 71 \\
2500 \pm 52\end{array}$ & $\begin{array}{r}-10.3 \pm 1.2 \\
-8.4 \pm 0.8\end{array}$ & $\begin{array}{l}0(1) \\
0(1)\end{array}$ & $\begin{array}{l}0.00017(1) \\
0.00014(1)\end{array}$ & $\begin{array}{l}0.00051(1) \\
0.00043(1)\end{array}$ \\
\hline 426513 & $\begin{array}{l}(295) \\
(300)\end{array}$ & $\begin{array}{l}2 \\
4\end{array}$ & $\begin{array}{l}2500 \pm 83 \\
2501 \pm 71\end{array}$ & $\begin{array}{l}-8.8 \pm 1.1 \\
-8.8 \pm 1.2\end{array}$ & $\begin{array}{l}0.00014(1) \\
0.00043(1)\end{array}$ & $\begin{array}{r}0.00073(1) \\
0.0022(1)\end{array}$ & $\begin{array}{l}0.0022(1) \\
0.0067(1)\end{array}$ \\
\hline 451623 & $\begin{array}{l}(48) \\
(50) \\
\end{array}$ & $\begin{array}{l}3 \\
4 \\
\end{array}$ & $\begin{array}{l}2498 \pm 52 \\
2498 \pm 71 \\
\end{array}$ & $\begin{array}{r}-10.8 \pm 0.8 \\
-7.9 \pm 1.2 \\
\end{array}$ & $\begin{array}{l}0.0025(1) \\
0.0029(1)\end{array}$ & $\begin{array}{l}0.013(1) \\
0.015(1) \\
\end{array}$ & $\begin{array}{r}0.04(1) \\
0.044(1) \\
\end{array}$ \\
\hline
\end{tabular}


Table A3. The influence of the number samples on the MSWD and PoF of a BFL. Data from stage 1 of the Sm-Nd system for the arrangement 362514-333333 after five (05) steps.

\begin{tabular}{|lllll|}
\hline $\begin{array}{l}\text { No. of } \\
\text { Samples }\end{array}$ & $\begin{array}{l}\text { Age range (Ma) } \\
\text { given by BFLs }\end{array}$ & $\begin{array}{l}\text { MSWD (PoF) } \\
\mathbf{2 \sigma}=\mathbf{0 . 0 1 \%}\end{array}$ & $\begin{array}{l}\text { MSWD (PoF) } \\
\mathbf{2 \sigma}=\mathbf{0 . 0 0 4 4 \%}\end{array}$ & $\begin{array}{l}\text { MSWD (PoF) } \\
\mathbf{2 \sigma}=\mathbf{0 . 0 0 2 5} \%\end{array}$ \\
\hline 6 & $2861 \pm 280-3400 \pm 110$ & $0.49-24(0.74-0)$ & $2.5-125(0.039-0)$ & $7.5-377(0)$ \\
12 & $2952 \pm 200-3343 \pm 230$ & $1.9-13(0.04-0)$ & $9.7-65(0)$ & $29-195(0)$ \\
18 & $3020 \pm 160-3277 \pm 130$ & $3.1-12(0)$ & $16-63(0)$ & $48-190(0)$ \\
24 & $3026 \pm 150-3285 \pm 120$ & $9-10.2(0)$ & $20-52(0)$ & $60-157(0)$ \\
30 & $3086 \pm 110-3238 \pm 120$ & $5.1-9.7(0)$ & $26-49(0)$ & $79-148(0)$ \\
36 & $3095 \pm 100-3212 \pm 120$ & $5.0-8.8(0)$ & $26-45(0)$ & $77-135(0)$ \\
\hline \multicolumn{2}{|l}{ A 3500 Ma isochron has been reset at 2500 Ma. Ages given at $2 \sigma=0.01 \%$ on ${ }^{143} \mathrm{Nd} /{ }^{144} \mathrm{Nd} \mathrm{\&} 0.1 \%$ on ${ }^{147} \mathrm{Sm} /{ }^{144} \mathrm{Nd}$} \\
\hline
\end{tabular}

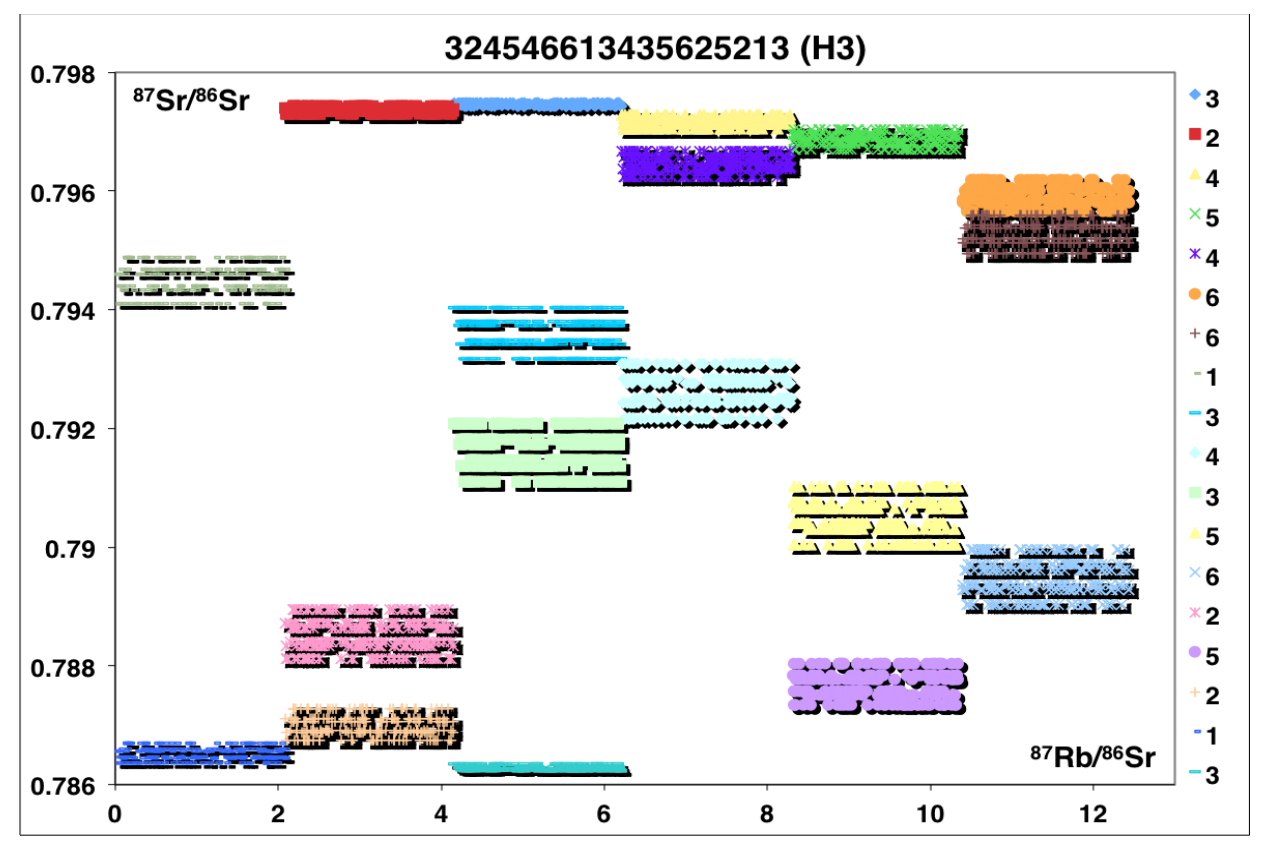

Fig. A5. Eighteen-layer Rb-Sr system of Table A5(a) in early stage 3. The Sr-ratios have homogenized at first decimal. Note FGIR is following the layer arrangement given in the legend.

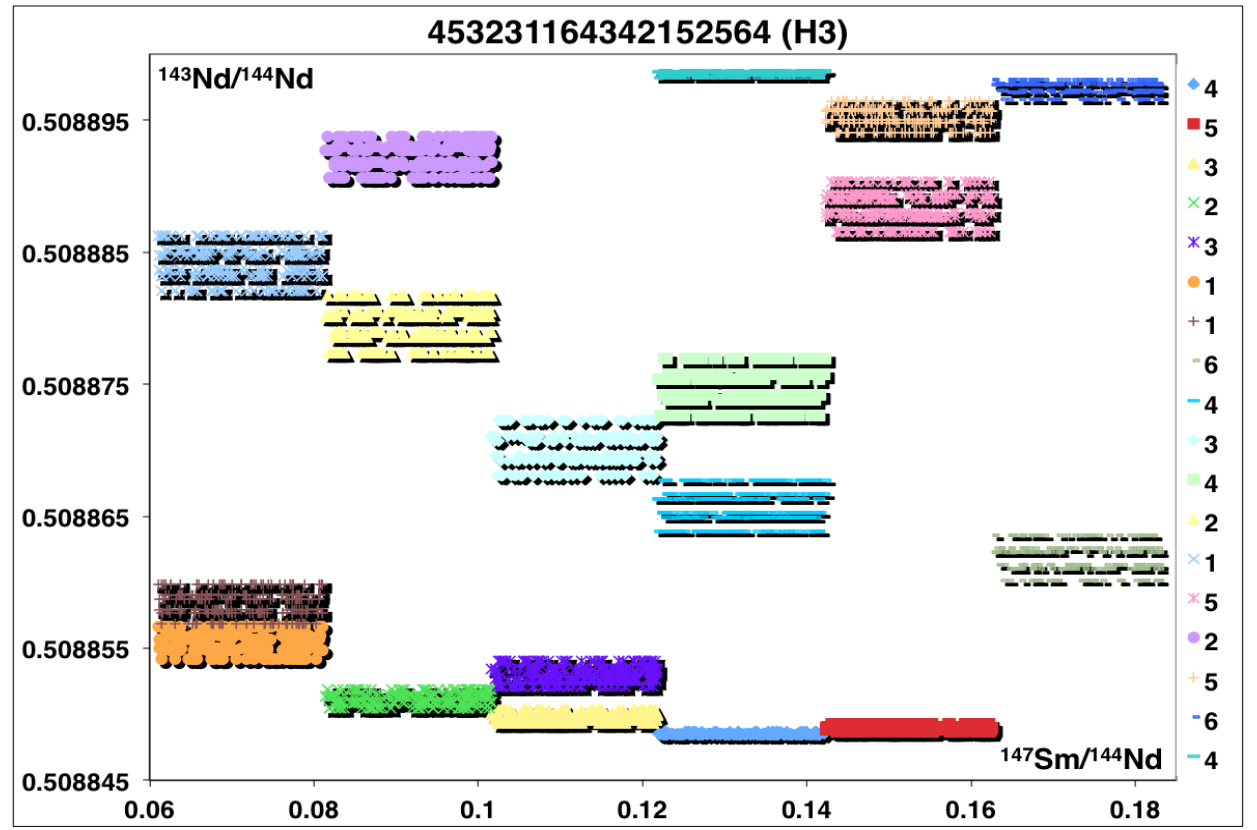

Fig. A6. Eighteen-layer Sm-Nd system of Table A5(b) in early stage 3. The Nd-ratios have homogenized at fourth decimal. Note FGIR is inverted with respect to the layer arrangement given in the legend. 
Table A4 (a). Details of a set of hundred BFLs for Rb-Sr data at each chosen step of isotopic resetting in five six-layer arrangements. Data from the three stages of isochron translation during resetting of a $3500 \mathrm{Ma} \mathrm{Rb-Sr}$ isochron at $2500 \mathrm{Ma}$ have been used for arrangements described in the text. A BFL contains two random samples from each layer. Note: Mean age approach the resetting age and $I_{S r}$ of BFLs approach $I_{S r}$ from the simulation only when the PoF $=1$. Initial $I_{S r}$ of BFLs from the stages 1 and 2 are sometimes unreliable as those do not overlap with $I_{S r}$ from the simulation.

\begin{tabular}{|c|c|c|c|c|c|c|c|}
\hline $\begin{array}{l}\text { Field } \\
\text { Relation } \\
\text { (Reset step) }\end{array}$ & Stage & $\begin{array}{l}\text { Age Range (Ma)\# } \\
\text { from BFLs }\end{array}$ & $\begin{array}{c}\text { Range of } \\
\text { Mean } \mathbf{I}_{S r} \\
\text { from BFLs }\end{array}$ & $\begin{array}{l}\text { Range of } \mathbf{I}_{\mathrm{Sr}} \\
\text { from } \\
\text { Simulation }\end{array}$ & $\begin{array}{l}\text { MSWD Range* } \\
\text { (PoF) } \\
2 \sigma=0.01 \%\end{array}$ & $\begin{array}{l}\text { MSWD Range* } \\
(\text { PoF) } \\
2 \sigma=0.0044 \%\end{array}$ & $\begin{array}{l}\text { MSWD Range* } \\
\text { (PoF) } \\
\mathbf{2 \sigma}=\mathbf{0 . 0 0 2 5} \%\end{array}$ \\
\hline $146532(5)$ & 1 & $3091 \pm 280-3598 \pm 430$ & $0.6970-0.7330$ & $0.7313-0.8412$ & $312-4026(0)$ & $314-4183(0)$ & $314-4211(0)$ \\
\hline $246513(5)$ & 1 & $2982 \pm 370-3573 \pm 460$ & $0.6930-0.7470$ & $0.7331-0.8413$ & $218-7837(0)$ & $220-10095(0)$ & $220-10599(0)$ \\
\hline $362514(5)$ & 1 & $2829 \pm 270-3431 \pm 360$ & $0.7020-0.7560$ & $0.7415-0.8357$ & $388-20353(0)$ & $391-50036(0)$ & $392-61073(0)$ \\
\hline $426513(5)$ & 1 & $2872 \pm 200-3455 \pm 320$ & $0.7040-0.7550$ & $0.7387-0.8407$ & $213-9310(0)$ & $215-10585(0)$ & $215-10833(0)$ \\
\hline $451623(5)$ & 1 & $2900 \pm 210-3417 \pm 320$ & $0.7030-0.7600$ & $0.7382-0.8344$ & $216-22776(0)$ & $217-31426(0)$ & $217-33492(0)$ \\
\hline $146532(200)$ & 2 & $2627 \pm 85-2755 \pm 100$ & $0.7661-0.7744$ & $0.7701-0.7975$ & $55-570(0)$ & $56-605(0)$ & $56-611(0)$ \\
\hline $246513(200)$ & 2 & $2569 \pm 82-2657 \pm 110$ & $0.7733-0.7804$ & $0.7745-0.7953$ & $71-377(0)$ & $72-417(0)$ & $72-425(0)$ \\
\hline $362514(200)$ & 2 & $2476 \pm 59-2533 \pm 61$ & $0.7833-0.7881$ & $0.7829-0.7905$ & $26-171(0)$ & $26-196(0)$ & $26-201(0)$ \\
\hline $426513(200)$ & 2 & $2508 \pm 94-2632 \pm 130$ & $0.7760-0.7853$ & $0.7738-0.7921$ & $112-1416(0)$ & $113-1712(0)$ & $113-1776(0)$ \\
\hline $451623(200)$ & 3 & $2510 \pm 150-2695 \pm 150$ & $0.7700-0.7860$ & $0.7715-0.8012$ & $319-1430(0)$ & $323-1555(0)$ & $324-1579(0)$ \\
\hline $146532(500)$ & 2 & $2508 \pm 36-2546 \pm 38$ & $0.7823-0.7853$ & $0.7820-0.7880$ & $21-222$ & $22-259(0)$ & $22-267(0)$ \\
\hline $246513(500)$ & 2 & $2504 \pm 25-2528 \pm 23$ & $0.7835-0.7856$ & $0.7832-0.7873$ & $7.4-75(0)$ & $7.5-87(0)$ & $7.5-90(0)$ \\
\hline $362514(500)$ & 3 & $2492 \pm 35-2515 \pm 28$ & $0.7844-0.7866$ & $0.7838-0.7883$ & $7.7-56(0)$ & $7.7-64(0)$ & $7.7-65(0)$ \\
\hline $426513(500)$ & 3 & $2495 \pm 54-2541 \pm 50$ & $0.7827-0.7865$ & $0.7814-0.7895$ & $33-300(0)$ & $33-352(0)$ & $33-363(0)$ \\
\hline $451623(500)$ & 3 & $2483 \pm 110-2593 \pm 85$ & $0.7792-0.7880$ & $0.7777-0.7942$ & $107-801(0)$ & $108-900(0)$ & $108-919(0)$ \\
\hline $146532(800)$ & 3 & $2494 \pm 21-2514 \pm 21$ & $0.7847-0.7864$ & $0.7842-0.7874$ & $9.6-73$ & $9.8-84(0)$ & $9.8-86(0)$ \\
\hline $246513(800)$ & 3 & $2496 \pm 13-2510 \pm 15$ & $0.7851-0.7863$ & $0.7848-0.7869$ & $2.5-30(0.0049-0)$ & $2.5-36(0.0045-0)$ & $2.6-37(0.0044-0)$ \\
\hline $362514(800)$ & 3 & $2496 \pm 17-2510 \pm 15$ & $0.7850-0.7862$ & $0.7847-0.7872$ & $2.7-19(0.0025-0)$ & $2.7-22(0.0023-0)$ & $2.7-23(0.0023-0)$ \\
\hline $426513(800)$ & 3 & $2498 \pm 32-2523 \pm 34$ & $0.7842-0.7861$ & $0.7836-0.7882$ & $10.2-100(0)$ & $10.3-116(0)$ & $10.3-120(0)$ \\
\hline $451623(800)$ & 3 & $2501 \pm 52-2552 \pm 55$ & $0.7814-0.7858$ & $0.7813-0.7906$ & $36-223(0)$ & $36-246(0)$ & $36-250(0)$ \\
\hline $146532(1500)$ & 3 & $2494 \pm 5-2507 \pm 5$ & $0.7850-0.7864$ & $0.7855-0.7864$ & $0.62-5.1(0.79-0)$ & $0.63-6(0.79-0)$ & $0.63-6.1(0.79-0)$ \\
\hline $246513(1500)$ & 3 & $2495 \pm 4-2503 \pm 6$ & $0.7857-0.7862$ & $0.7857-0.7862$ & $0.22-2.1(0.994-0.023)$ & $0.23-2.4(0.994-0.0087)$ & $0.23-2.4(0.994-0.0072)$ \\
\hline $362514(1500)$ & 3 & $2498 \pm 4-2503 \pm 6$ & $0.7857-0.7861$ & $0.7856-0.7863$ & $0.23-1.4(0.994-0.2)$ & $0.23-1.6(0.994-0.11)$ & $0.23-1.6(0.994-0.1)$ \\
\hline $426513(1500)$ & 3 & $2493 \pm 5-2511 \pm 9$ & $0.7851-0.7865$ & $0.7854-0.7865$ & $0.76-9.7(0.67-$ & $0.77-12(0.66-0)$ & $0.77-13(0.66-0)$ \\
\hline $451623(1500)$ & 3 & $2501 \pm 20-2515 \pm 17$ & $0.7848-0.7858$ & $0.7847-0.7872$ & $2.4-21(0.0078-0)$ & $2.4-25(0.0068-0)$ & $2.4-25(0.0069-0)$ \\
\hline $146532(2200)$ & 3 & $2498 \pm 5-2503 \pm 4$ & $0.7858-0.7860$ & $0.7858-0.7860$ & $0.038-0.31(1-0.98)$ & $0.038-0.37(1-0.96)$ & $0.038-0.38(1-0.96)$ \\
\hline $246513(2000)$ & 3 & $2498 \pm 4-2501 \pm 9$ & $0.7858-0.7860$ & $0.7858-0.7860$ & $0.029-0.24(1-0.992)$ & $0.029-0.27(1-0.99)$ & $0.029-0.27(1-0.99)$ \\
\hline $362514(2200)$ & 3 & $2499 \pm 4-2501 \pm 5$ & $0.7859-0.7860$ & $0.7859-0.7860$ & $0.016-0.092(1)$ & $0.017-0.107(1)$ & $0.017-0.111(1)$ \\
\hline $426513(2400)$ & 3 & $2498 \pm 4-2502 \pm 10$ & $0.7858-0.7860$ & $0.7858-0.7860$ & $0.028-0.29(1-0.98)$ & $0.028-0.34(1-0.97)$ & $0.028-0.35(1-0.97)$ \\
\hline $451623(2600)$ & 3 & $2499 \pm 5-2502 \pm 5$ & $0.7858-0.7860$ & $0.7858-0.7861$ & $0.041-0.23(1-0.994)$ & $0.042-0.26(1-0.99)$ & $0.042-0.26(1-0.99)$ \\
\hline
\end{tabular}

$*$ All calculations used a $2 \sigma$ error of $0.5 \%$ on ${ }^{87} \mathrm{Rb}{ }^{86} \mathrm{Sr}$ ratios. \#The range of ages from BFLs is given for $2 \sigma$ error of $0.01 \%$ on ${ }^{87} \mathrm{Sr}{ }^{86} \mathrm{Sr}$ ratios. 
Table A4 (b): Details of a set of hundred BFLs for Sm-Nd data at each chosen step of isotopic resetting in five six-layer arrangements. Data from the three stages of isochron translation during resetting of a $3500 \mathrm{Ma} \mathrm{Sm}-\mathrm{Nd}$ isochron at $2500 \mathrm{Ma}$ have been used for arrangements described in the text. A BFL contains two random samples from each layer. Note: Mean age approach the resetting age and $\varepsilon N d$ of BFLs approach $\varepsilon N d$ from the simulation only when the PoF $=1 . \varepsilon N d$ of BFLs from the stages 1 and 2 are sometimes unreliable as those do not overlap with $\varepsilon N d$ from the simulation.

\begin{tabular}{|c|c|c|c|c|c|c|c|}
\hline $\begin{array}{l}\text { Field Relation } \\
\text { (Reset Step) }\end{array}$ & Stage & $\begin{array}{l}\text { Age range (Ma)\# } \\
\text { from BFLs }\end{array}$ & $\begin{array}{l}\text { Range of } \\
\text { Mean } \varepsilon N d \\
\text { from BFLs }\end{array}$ & $\begin{array}{l}\text { Range of } \\
\text { ENd from } \\
\text { Simulation }\end{array}$ & $\begin{array}{l}\text { MSWD Range* } \\
(\text { PoF) } \\
2 \sigma=0.01 \%\end{array}$ & $\begin{array}{l}\text { MSWD Range* } \\
\text { (PoF) } \\
\mathbf{2 \sigma}=\mathbf{0 . 0 0 4 4 \%}\end{array}$ & $\begin{array}{l}\text { MSWD Range* } \\
\text { (PoF) } \\
\mathbf{2 \sigma}=\mathbf{0 . 0 0 2 5 \%}\end{array}$ \\
\hline $\begin{array}{l}146532(5) \\
246513(5) \\
362514(5) \\
426513(5) \\
451623(5)\end{array}$ & $\begin{array}{l}1 \\
1 \\
1 \\
1 \\
1\end{array}$ & $\begin{array}{l}3188 \pm 170-3567 \pm 220 \\
3103 \pm 250-3448 \pm 190 \\
2952 \pm 200-3343 \pm 230 \\
3023 \pm 280-3392 \pm 220 \\
2918 \pm 170-3359 \pm 200\end{array}$ & $\begin{array}{l}-2.63 \text { to }+0.68 \\
-9.55 \text { to }+5.27 \\
-5.57 \text { to }-1.18 \\
-10.82 \text { to }+5.00 \\
-5.47 \text { to }-1.75\end{array}$ & $\begin{array}{l}-15.18 \text { to }-3.63 \\
-14.99 \text { to }-3.64 \\
-14.80 \text { to }-4.03 \\
-14.99 \text { to }-3.68 \\
-14.61 \text { to }-4.11\end{array}$ & $\begin{array}{l}1.3-12(0.2-0) \\
1.5-13(0.12-0) \\
1.9-13(0.04-0) \\
2.6-13(0.0037-0) \\
1.13-12(0.34-0)\end{array}$ & $\begin{array}{l}6.8-64(0) \\
7.9-64(0) \\
9.7-65(0) \\
13.0-65(0) \\
5.7-62(0)\end{array}$ & $\begin{array}{l}20-191(0) \\
24-195(0) \\
29-195(0) \\
40-194(0) \\
17-188(0)\end{array}$ \\
\hline $\begin{array}{l}146532(200) \\
246513(200) \\
362514(200) \\
426513(200) \\
451623(200)\end{array}$ & $\begin{array}{l}2 \\
2 \\
3 \\
2 \\
3\end{array}$ & $\begin{array}{l}2641 \pm 62-2719 \pm 77 \\
2586 \pm 120-2667 \pm 92 \\
2511 \pm 110-2585 \pm 120 \\
2543 \pm 130-2624 \pm 130 \\
2510 \pm 110-2581 \pm 77\end{array}$ & $\begin{array}{l}-8.11 \text { to }-7.21 \\
-8.50 \text { to }-7.82 \\
-9.21 \text { to }-8.53 \\
-8.82 \text { to }-8.12 \\
-9.27 \text { to }-8.59\end{array}$ & $\begin{array}{l}-10.59 \text { to }-8.22 \\
-10.77 \text { to }-8.40 \\
-10.31 \text { to }-8.42 \\
-10.82 \text { to }-8.59 \\
-10.29 \text { to }-8.41\end{array}$ & $\begin{array}{l}0.13-1.09(0.999-0.37) \\
0.9-2.3(0.53-0.011) \\
1.8-2.6(0.047-0.004) \\
1.8-2.7(0.054-0.0023) \\
1.4-2.1(0.15-0.021)\end{array}$ & $\begin{array}{l}0.67-5.6(0.76-0) \\
4.6-11.8(0) \\
9.5-13(0) \\
9.3-14(0) \\
7.4-10.8(0)\end{array}$ & $\begin{array}{l}2-17(0.0261-0) \\
14-36(0) \\
29-40(0) \\
28-43(0) \\
22-33(0)\end{array}$ \\
\hline $\begin{array}{l}146532(500) \\
246513(500) \\
362514(500) \\
426513(500) \\
451623(500)\end{array}$ & $\begin{array}{l}2 \\
2 \\
3 \\
3 \\
3\end{array}$ & $\begin{array}{l}2514 \pm 65-2523 \pm 77 \\
2509 \pm 28-2538 \pm 75 \\
2503 \pm 64-2550 \pm 73 \\
2506 \pm 81-2545 \pm 76 \\
2495 \pm 76-2541 \pm 76\end{array}$ & $\begin{array}{l}-9.21 \text { to }-9.14 \\
-9.28 \text { to }-9.01 \\
-9.36 \text { to }-8.92 \\
-9.95 \text { to }-9.30 \\
-9.40 \text { to }-8.97\end{array}$ & $\begin{array}{l}-9.50 \text { to }-9.24 \\
-9.81 \text { to }-9.07 \\
-9.92 \text { to }-8.80 \\
-9.94 \text { to }-8.89 \\
-9.86 \text { to }-8.85\end{array}$ & $\begin{array}{l}0.0032-0.015(1-1) \\
0.25-0.38(0.992-0.96) \\
0.58-0.79(0.83-0.64) \\
0.47-0.70(0.91-0.72) \\
0.45-0.65(0.92-0.77)\end{array}$ & $\begin{array}{l}0.016-0.075(1) \\
1.3-1.9(0.25-0.036) \\
3.0-4.1(0.001-0) \\
2.4-3.6(0.0069-0.0001) \\
2.3-3.3(0.011-0.0002)\end{array}$ & $\begin{array}{l}0.05-0.23(1-0.994) \\
3.8-5.9(0) \\
9-12(0) \\
7.4-11(0) \\
7-10.1(0)\end{array}$ \\
\hline $\begin{array}{l}146532(800) \\
246513(800) \\
362514(800) \\
426513(800) \\
451623(800)\end{array}$ & $\begin{array}{l}2 \\
3 \\
3 \\
3 \\
3\end{array}$ & $\begin{array}{l}2502 \pm 70-2501 \pm 70 \\
2500 \pm 77-2516 \pm 71 \\
2504 \pm 32-2531 \pm 34 \\
2498 \pm 71-2530 \pm 82 \\
2501 \pm 66-2524 \pm 34\end{array}$ & $\begin{array}{l}-9.37 \text { to }-9.30 \\
-9.35 \text { to }-9.20 \\
-9.31 \text { to }-9.07 \\
-9.37 \text { to }-9.06 \\
-9.35 \text { to }-9.11\end{array}$ & $\begin{array}{l}-9.39 \text { to }-9.34 \\
-9.58 \text { to }-9.15 \\
-9.67 \text { to }-9.04 \\
-9.66 \text { to }-9.07 \\
-9.64 \text { to }-9.07\end{array}$ & $\begin{array}{l}0.00064-0.00115(1) \\
0.081-0.118(1) \\
0.18-0.26(0.998-0.99) \\
0.16-0.24(0.998-0.993) \\
0.15-0.21(0.999-0.995)\end{array}$ & $\begin{array}{l}0.0033-0.0059(1) \\
0.41-0.61(0.94-0.81) \\
0.91-1.4(0.52-0.2) \\
0.84-1.2(0.58-0.28) \\
0.77-1.08(0.66-0.37)\end{array}$ & $\begin{array}{l}0.01-0.018(1) \\
1.3-1.9(0.24-0.046) \\
2.8-4.1(0.002-0) \\
2.6-3.7(0.0041-0.0001) \\
2.3-3.3(0.0096-0.0003)\end{array}$ \\
\hline $\begin{array}{l}146532(1000) \\
246513(1500) \\
362514(1700) \\
426513(1650) \\
451623(1650)\end{array}$ & $\begin{array}{l}3 \\
3 \\
3 \\
3 \\
3\end{array}$ & $\begin{array}{l}2500 \pm 68-2501 \pm 76 \\
2500 \pm 72-2503 \pm 72 \\
2501 \pm 67-2504 \pm 67 \\
2501 \pm 69-2504 \pm 68 \\
2500 \pm 73-2504 \pm 73 \\
\end{array}$ & $\begin{array}{l}-9.349 \text { to }-9.355 \\
-9.35 \text { to }-9.34 \\
-9.35 \text { to }-9.31 \\
-9.35 \text { to }-9.31 \\
-9.35 \text { to }-9.31\end{array}$ & $\begin{array}{l}-9.37 \text { to }-9.35 \\
-9.41 \text { to }-9.30 \\
-9.41 \text { to }-9.30 \\
-9.41 \text { to }-9.30 \\
-9.41 \text { to }-9.30 \\
\end{array}$ & $\begin{array}{l}0.00032-0.00044(1) \\
0.0064-0.0082(1) \\
0.0063-0.0082(1) \\
0.0066-0.0089(1) \\
0.0060-0.0085(1)\end{array}$ & $\begin{array}{l}0.0017-0.0022(1) \\
0.033-0.042(1) \\
0.032-0.042(1) \\
0.034-0.044(1) \\
0.030-0.041(1)\end{array}$ & $\begin{array}{l}0.0051-0.0068(1) \\
0.1-0.13(1) \\
0.098-0.13(1) \\
0.103-0.13(1) \\
0.091-0.13(1)\end{array}$ \\
\hline
\end{tabular}


Table A5 (a). Details of a set of hundred BFLs for Rb-Sr data at each chosen step of isotopic resetting in an eighteen-layer arrangement. All layers are having equal thickness. Data from the three stages of isochron translation during resetting of a $3500 \mathrm{Ma}$ Rb-Srisochron at 2500 Ma have been used. At the last step given, 50\% of the BFLs showed PoF = 1 at all $2 \sigma$ when MSWD $\leq 0.38$.

\begin{tabular}{|c|c|c|c|c|c|c|c|}
\hline $\begin{array}{l}\text { Resetting } \\
\text { Step }\end{array}$ & Stage & $\begin{array}{l}\text { Range of Ages\# } \\
\text { (Ma) from BFLs }\end{array}$ & $\begin{array}{l}\text { Range of } \\
{\text { Mean } I_{S r} \text { from }}_{\text {BFLs }} \\
\end{array}$ & $\begin{array}{c}\text { Range of } \mathrm{I}_{\mathrm{Sr}} \\
\text { Directly from } \\
\text { Simulation }\end{array}$ & $\begin{array}{c}\text { MSWD }(\text { PoF })^{*} \\
2 \sigma=0.01 \%\end{array}$ & $\begin{array}{c}\text { MSWD (PoF)* } \\
2 \sigma=0.0044 \%\end{array}$ & $\begin{array}{c}\text { MSWD }(\text { PoF })^{*} \\
2 \sigma=0.0025 \%\end{array}$ \\
\hline 5 & 1 & $3100 \pm 140-3314 \pm 110$ & $0.7160-0.7370$ & $0.7217-0.8629$ & $651-32009(0)$ & $661-90312(0)$ & $663-98014(0)$ \\
\hline 200 & 2 & $2630 \pm 83-2679 \pm 90$ & $0.7758-0.7807$ & $0.7601-0.8107$ & $1651-15186(0)$ & $1749-29487(0)$ & $1768-35341(0)$ \\
\hline 400 & 2 & $2569 \pm 75-2606 \pm 68$ & $0.7827-0.7858$ & $0.7695-0.8035$ & $1140-10163(0)$ & $1180-44220(0)$ & $1187-130000(0)$ \\
\hline 800 & 2 & $2536 \pm 51-2561 \pm 51$ & $0.7869-0.7892$ & $0.7781-0.7996$ & $608-5252(0)$ & $633-19760(0)$ & $638-36356(0)$ \\
\hline 2000 & 3 & $2515 \pm 29-2526 \pm 27$ & $0.7901-0.7912$ & $0.7862-0.7975$ & $139-763(0)$ & $143-1472(0)$ & $144-1784(0)$ \\
\hline 6000 & 3 & $2502 \pm 6-2506 \pm 6$ & $0.7920-0.7923$ & $0.7915-0.7935$ & $4-25(0)$ & $4.2-76(0)$ & $4.2-88(0)$ \\
\hline 10000 & 3 & $2499 \pm 2-2502 \pm 2$ & $0.7923-0.7925$ & $0.7923-0.7927$ & $0.19-0.7(1-0.91)$ & $0.2-2.9(1-0)$ & $0.2-8.2(1-0)$ \\
\hline
\end{tabular}

${ }^{*}$ All calculations used a $2 \sigma$ error of $0.5 \%$ on ${ }^{87} \mathrm{Rb}{ }^{86} \mathrm{Sr}$ ratios. \#The range of ages from BFLs is given for $2 \sigma$ error of $0.01 \%$ on ${ }^{87} \mathrm{Sr}{ }^{86} \mathrm{Sr}$ ratios.

Table A5 (b). Details of a set of hundred BFLs for Sm-Nd data at each chosen step of isotopic resetting in an eighteen-layer arrangement. Data from the three stages of isochron translation during resetting of a $3500 \mathrm{Ma} S \mathrm{Sm}-\mathrm{Nd}$ isochron at $2500 \mathrm{Ma}$ have been used. All layers are having equal thickness. At the last step given, all BFLs showed PoF $=1$ at all $2 \sigma$ below different threshold MSWD values.

\begin{tabular}{|c|c|c|c|c|c|c|c|}
\hline \multicolumn{8}{|c|}{ Layer Arrangement - $\mathbf{4 6 5 2 5 1 2 4 3 4 6 1 1 3 2 3 5 4}$} \\
\hline $\begin{array}{l}\text { Resetting } \\
\text { Step }\end{array}$ & Stage & $\begin{array}{l}\text { Range of Ages\# } \\
\text { (Ma) from BFLs }\end{array}$ & $\begin{array}{l}\text { Range of } \\
\text { Mean } \varepsilon N d \\
\text { from BFLs }\end{array}$ & $\begin{array}{c}\text { Range of } \\
\text { ENd from } \\
\text { Simulation }\end{array}$ & $\begin{array}{l}\text { MSWD }(\text { PoF })^{*} \\
2 \sigma=0.01 \%\end{array}$ & $\begin{array}{l}\text { MSWD (PoF)* } \\
2 \sigma=0.0044 \%\end{array}$ & $\begin{array}{l}\text { MSWD (PoF)* } \\
2 \sigma=0.0025 \%\end{array}$ \\
\hline 5 & 1 & $3090 \pm 130-3298 \pm 100$ & -4.38 to -1.64 & -16.55 to -3.95 & $4.3-13(0)$ & $22-66(0)$ & $66-197(0)$ \\
\hline 200 & 2 & $2630 \pm 92-2671 \pm 82$ & -8.94 to -8.54 & -11.90 to -7.45 & $4.2-5.4(0)$ & $21-28(0)$ & $64-84(0)$ \\
\hline 400 & 2 & $2573 \pm 68-2597 \pm 70$ & -9.58 to -9.34 & -11.26 to -8.29 & $2.8-3.3(0)$ & $14-17(0)$ & $44-51(0)$ \\
\hline 800 & 2 & $2536 \pm 54-2557 \pm 53$ & -9.92 to -9.70 & - 10.92 to -9.04 & $1.5-1.8(0.0038-0.025)$ & $7.8-9.1(0)$ & $24-28(0)$ \\
\hline 2000 & 3 & $2514 \pm 38-2524 \pm 40$ & -10.15 to -10.05 & -10.74 to -9.75 & $0.47-0.51(0.991-0.996)$ & $2.4-2.6(0)$ & $7.4-8.0(0)$ \\
\hline 4000 & 3 & $2505 \pm 38-2510 \pm 41$ & -10.25 to -10.20 & -10.51 to -10.09 & $0.086-0.093(1)$ & $0.44-0.48(0.996-0.998)$ & $1.4-1.5(0.042-0.083)$ \\
\hline 6000 & 3 & $2502 \pm 40-2504 \pm 37$ & -10.28 to -10.25 & -10.39 to -10.21 & $0.016-0.017(1)$ & $0.082-0.089(1)$ & $0.25-0.27(1)$ \\
\hline
\end{tabular}


Table A6 summarizes BFLs for Rb-Sr data from six-layer arrangements at two steps of isotopic resetting in the $3^{\text {rd }}$ Stage. Some BFLs give a mean age identical to the $2500 \mathrm{Ma}$ age used in the simulation, but those have MSWD higher than some other BFLs that give mean ages deviating from it. If one relies on MSWD, the
BFLs deviating from the true resetting age will be preferred in a natural situation where the age of resetting is unknown, but if one relies on FGIR one can derive accurate ages from data leading to both $2500 \mathrm{Ma}$ and other BFLs (see TableA10).

Table A6. A comparison of BFLs showing Rb-Sr ages of $2500 \mathrm{Ma}$ and other ages within stage 3. Note that some BFLs showing other ages have lower MSWD than 2500 Ma BFLs.

\begin{tabular}{|c|c|c|c|c|c|c|c|c|}
\hline $\begin{array}{l}\text { Layer } \\
\text { Relation }\end{array}$ & $\begin{array}{l}\text { Reset } \\
\text { step }\end{array}$ & $\begin{array}{l}\text { IT } \\
\text { Stage }\end{array}$ & $\begin{array}{l}\text { Age Range (Ma) } \\
\text { from BFLs* }\end{array}$ & $\begin{array}{l}\text { MSWD } \\
\text { Range }\end{array}$ & $\begin{array}{l}2500 \mathrm{Ma} \\
\text { BFLs }\end{array}$ & MSWD & $\begin{array}{l}\text { Other } \\
\text { BFLs }\end{array}$ & MSWD \\
\hline \multirow[t]{2}{*}{146532} & 800 & 3 & $2494 \pm 21-2514 \pm 21$ & $9.6-73$ & $\begin{array}{l}2500 \pm 24 \\
2500 \pm 20 \\
2500 \pm 18\end{array}$ & $\begin{array}{l}10.2 \\
14 \\
28\end{array}$ & $\begin{array}{l}2511 \pm 18 \\
2496 \pm 24 \\
2514 \pm 21\end{array}$ & $\begin{array}{l}9.6 \\
10 \\
10.8\end{array}$ \\
\hline & 1000 & 3 & $2495 \pm 17-2508 \pm 14$ & $3.7-36$ & $\begin{array}{l}2500 \pm 15 \\
2500 \pm 13 \\
2500 \pm 12\end{array}$ & $\begin{array}{l}7.7 \\
16 \\
28\end{array}$ & $\begin{array}{l}2495 \pm 17 \\
2505 \pm 18 \\
2508 \pm 13\end{array}$ & $\begin{array}{l}3.7 \\
4.4 \\
4.9\end{array}$ \\
\hline \multirow[t]{2}{*}{246513} & 800 & 3 & $2496 \pm 13-2510 \pm 15$ & $2.5-30$ & $\begin{array}{l}2500 \pm 16 \\
2500 \pm 12 \\
2500 \pm 13\end{array}$ & $\begin{array}{l}5.4 \\
15 \\
22\end{array}$ & $\begin{array}{l}2510 \pm 15 \\
2507 \pm 13 \\
2509 \pm 14\end{array}$ & $\begin{array}{l}2.5 \\
2.9 \\
3.4\end{array}$ \\
\hline & 1000 & 3 & $2494 \pm 8-2511 \pm 9$ & $1.17-10.1$ & $\begin{array}{l}2500 \pm 14 \\
2500 \pm 11 \\
2500 \pm 11\end{array}$ & $\begin{array}{l}1.9 \\
5.1 \\
9.3\end{array}$ & $\begin{array}{l}2508 \pm 6 \\
2510 \pm 7 \\
2511 \pm 9\end{array}$ & $\begin{array}{l}1.17 \\
1.5 \\
1.2\end{array}$ \\
\hline \multirow[t]{2}{*}{362514} & 800 & 3 & $2496 \pm 17-2510 \pm 15$ & $2.7-19$ & $\begin{array}{l}2500 \pm 18 \\
2500 \pm 12 \\
2500 \pm 15\end{array}$ & $\begin{array}{l}5.6 \\
9 \\
12\end{array}$ & $\begin{array}{l}2509 \pm 19 \\
2510 \pm 15 \\
2508 \pm 18\end{array}$ & $\begin{array}{l}2.7 \\
2.7 \\
3.5\end{array}$ \\
\hline & 1000 & 3 & $2497 \pm 11-2512 \pm 8$ & $1.3-9.2$ & $\begin{array}{l}2500 \pm 12 \\
2500 \pm 12 \\
2500 \pm 10\end{array}$ & $\begin{array}{l}2.3 \\
5.5 \\
9.2\end{array}$ & $\begin{array}{l}2508 \pm 6 \\
2512 \pm 8 \\
2507 \pm 13\end{array}$ & $\begin{array}{l}1.3 \\
1.4 \\
2.1\end{array}$ \\
\hline \multirow[t]{2}{*}{426513} & 800 & 3 & $2498 \pm 32-2523 \pm 34$ & $10.2-100$ & $\begin{array}{l}2500 \pm 28 \\
2500 \pm 25 \\
2500 \pm 21\end{array}$ & $\begin{array}{l}32 \\
43 \\
44\end{array}$ & $\begin{array}{l}2519 \pm 24 \\
2515 \pm 27 \\
2523 \pm 34\end{array}$ & $\begin{array}{l}10.2 \\
11.2 \\
12\end{array}$ \\
\hline & 1000 & 3 & $2496 \pm 21-2516 \pm 16$ & $4.3-51$ & $\begin{array}{l}2500 \pm 19 \\
2500 \pm 16 \\
2500 \pm 15\end{array}$ & $\begin{array}{l}9.7 \\
23 \\
46\end{array}$ & $\begin{array}{l}2511 \pm 18 \\
2516 \pm 16 \\
2509 \pm 20\end{array}$ & $\begin{array}{l}4.3 \\
4.4 \\
5.2\end{array}$ \\
\hline \multirow[t]{2}{*}{451623} & 800 & 3 & $2501 \pm 52-2552 \pm 55$ & $36-223$ & None & - & $\begin{array}{l}2538 \pm 61 \\
2544 \pm 46 \\
2513 \pm 56\end{array}$ & $\begin{array}{l}36 \\
41 \\
62\end{array}$ \\
\hline & 1000 & 3 & $2506 \pm 40-2532 \pm 34$ & $18-124$ & None & - & $\begin{array}{l}2521 \pm 37 \\
2519 \pm 32 \\
2506 \pm 40\end{array}$ & $\begin{array}{l}18 \\
19 \\
21\end{array}$ \\
\hline
\end{tabular}

*All calculations used a $2 \sigma$ error of $0.5 \%$ on ${ }^{87} \mathrm{Rb}{ }^{86} \mathrm{Sr}$ ratios and $0.01 \%$ on ${ }^{87} \mathrm{Sr}{ }^{86} \mathrm{Sr}$ ratios. 
Table A7. An example calculation of age range of FGIR for a BFL. The BFL is an errorchron for data from the $3^{\text {rd }}$ stage (500 steps) of 451623-333333 and does not give a FGIR at the mean age suggested. But the data give a FGIR between 2481 Ma and 2514 Ma, with a mean age of 2497 Ma close to the 2500 Ma age that is used in the simulation.

\begin{tabular}{|c|c|c|c|c|c|c|}
\hline $\begin{array}{l}\text { Sample } \\
\text { Coordinates } \\
\text { (Field Order) }\end{array}$ & ${ }^{87} \mathrm{Rb} /{ }^{86} \mathrm{Sr}$ & ${ }^{87} \mathrm{Sr} /{ }^{86} \mathrm{Sr}$ & $\begin{array}{l}\text { FGIR from } \\
\text { Simulation } \\
451623 @(500) \\
\text { FGIR } \square\end{array}$ & $\begin{array}{l}\text { Initial Ratio } \\
\text { @ BFL age } \\
\text { FGIR } \text {. }\end{array}$ & $\begin{array}{l}\text { Initial Ratio } \\
\text { @ } 2481 \text { Ma } \\
\text { FGIR ■ }\end{array}$ & $\begin{array}{l}\text { Initial Ratio } \\
\text { @ } 2514 \text { Ma } \\
\text { FGIR ■ }\end{array}$ \\
\hline$\{6,2, A\}$ & 5.9396 & 1.008885 & 0.794242 & 0.791882 & 0.795902 & 0.793019 \\
\hline$\{6,2, D\}$ & 7.2480 & 1.055756 & 0.793828 & 0.790949 & 0.795854 & 0.792335 \\
\hline$\{5,3, G\}$ & 9.0507 & 1.120049 & 0.792977 & 0.789381 & 0.795507 & 0.791112 \\
\hline$\{4,2, I\}$ & 8.1271 & 1.085792 & 0.792099 & 0.788870 & 0.794370 & 0.790425 \\
\hline$\{3,2,0\}$ & 1.0652 & 0.826975 & 0.788482 & 0.788059 & 0.788780 & 0.788262 \\
\hline$\{5,3, P\}$ & 1.2756 & 0.833707 & 0.787608 & 0.787102 & 0.787965 & 0.787346 \\
\hline$\{5,5, T\}$ & 11.3364 & 1.194413 & 0.784743 & 0.780238 & 0.787911 & 0.782407 \\
\hline$\{5,1, \mathrm{U}\}$ & 11.9882 & 1.217439 & 0.784213 & 0.779449 & 0.787564 & 0.781743 \\
\hline$\{3,6, Y\}$ & 4.9251 & 0.959553 & 0.781572 & 0.779615 & 0.782949 & 0.780558 \\
\hline$\{1,4, A A\}$ & 0.8090 & 0.809669 & 0.780434 & 0.780113 & 0.780661 & 0.780268 \\
\hline$\{5,3, A F\}$ & 5.8958 & 0.991377 & 0.778316 & 0.775974 & 0.779964 & 0.777102 \\
\hline$\{3,4, \mathbf{A J}\}$ & 3.1835 & 0.892780 & 0.777736 & 0.776472 & 0.778626 & 0.777081 \\
\hline BFL age $2527 \pm 73$ & $=0.78$ & $075, M S W$ & $556(2 \sigma=0.01 \%)$ & \multicolumn{3}{|c|}{ Age from $F G I R \approx 2497 \pm 16 \mathrm{Ma}, I R=0.7861 \pm 0.0083$} \\
\hline
\end{tabular}


Table A8. Comparison of Rb-Sr ages derived from BFLs and FGIR. MSWDs of BFLs at $2 \sigma$ of $0.0044 \%-0.0025 \%$ of many laboratories would be much higher (Table A4a, A5b) but give accurate ages from FGIR.

\begin{tabular}{|c|c|c|c|c|c|c|c|}
\hline \multirow{2}{*}{\multicolumn{2}{|c|}{$\begin{array}{l}\text { Layer } \\
\text { Relationship } \\
\text { Reset Step }\end{array}$}} & \multicolumn{3}{|c|}{ Result from BFL } & \multicolumn{3}{|c|}{ Result from FGIR fitting } \\
\hline & & \multirow{2}{*}{$\begin{array}{l}\text { Age (Ma) } \\
2511 \pm 31\end{array}$} & $\begin{array}{c}\text { Initial } \\
\text { Ratio }\end{array}$ & \multirow{2}{*}{$\begin{array}{c}\text { MSWD } \\
12 \\
\end{array}$} & \multirow{2}{*}{$\begin{array}{c}\begin{array}{c}\text { Age Range } \\
\text { for FGIR } \\
\text { (Ma) }\end{array} \\
2495-2507\end{array}$} & \multirow{2}{*}{$\begin{array}{c}\begin{array}{c}\text { Mean Age } \\
\text { (Ma) }\end{array} \\
2501 \pm 6\end{array}$} & \multirow{2}{*}{$\begin{array}{r}\text { Initial Ratio } \\
0.7859 \pm 23\end{array}$} \\
\hline 362514 & 500 & & $0.7849 \pm 29$ & & & & \\
\hline & 500 & $2506 \pm 28$ & $0.7855 \pm 25$ & 29 & $2499-2501$ & $2500 \pm 1$ & $0.7860 \pm 22$ \\
\hline & 500 & $2506 \pm 27$ & $0.7856 \pm 23$ & 47 & $2497-2501$ & $2499 \pm 2$ & $0.7861 \pm 22$ \\
\hline & 1000 & $2508.6 \pm 5.5$ & $0.7852 \pm 03$ & 1.5 & 2499-2502 & $2500.5 \pm 1.5$ & $0.7859 \pm 09$ \\
\hline & 1000 & $2501 \pm 9.4$ & $0.7859 \pm 06$ & 8.9 & $2499.7-2501$ & $2500.5 \pm 0.7$ & $0.7859 \pm 09$ \\
\hline \multirow[t]{5}{*}{426513} & 500 & $2513 \pm 39$ & $0.7847 \pm 42$ & 48 & $2490-2502$ & $2496 \pm 6$ & $0.7860 \pm 39$ \\
\hline & 500 & $2504 \pm 45$ & $0.7856 \pm 43$ & 125 & $2499-2503$ & $2501 \pm 2$ & $0.7852 \pm 39$ \\
\hline & 500 & $2512 \pm 41$ & $0.7848 \pm 39$ & 228 & $2498-2502$ & $2500 \pm 2$ & $0.7854 \pm 39$ \\
\hline & 1000 & $2511 \pm 21$ & $0.7850 \pm 19$ & 5.5 & $2498-2501$ & $2499.5 \pm 1.5$ & $0.7860 \pm 16$ \\
\hline & 1000 & $2503 \pm 21$ & $0.7858 \pm 16$ & 49 & $2497-2501$ & $2498.8 \pm 1.8$ & $0.7860 \pm 15$ \\
\hline \multirow[t]{5}{*}{451623} & 500 & $2574 \pm 76$ & $0.7799 \pm 69$ & 135 & $2483-2521$ & $2502 \pm 19$ & $0.7856 \pm 79$ \\
\hline & 500 & $2577 \pm 100$ & $0.7800 \pm 88$ & 336 & 2495-2509 & $2502 \pm 7$ & $0.7858 \pm 82$ \\
\hline & 500 & $2527 \pm 73$ & $0.7840 \pm 75$ & 556 & $2481-2514$ & $2497 \pm 16$ & $0.7862 \pm 83$ \\
\hline & 1000 & $2523 \pm 30$ & $0.7839 \pm 30$ & 20 & $2496-2507$ & $2501.5 \pm 5.5$ & $0.7858 \pm 31$ \\
\hline & 1000 & $2520 \pm 34$ & $0.7845 \pm 31$ & 79 & $2494-2501$ & $2497.5 \pm 3.5$ & $0.7861 \pm 31$ \\
\hline
\end{tabular}


Table A9. Comparison of Sm-Nd ages derived from BFLs and FGIR. BFLs will give MSWD > 1 at $0.0044 \%-0.0025 \% 2 \sigma$ error of many laboratories (Table A4b, A5b) but give accurate ages from FGIR.

\begin{tabular}{|c|c|c|c|c|c|c|c|}
\hline \multirow{2}{*}{\multicolumn{2}{|c|}{$\begin{array}{l}\text { Layer } \\
\text { Relationship } \\
\text { Reset Step }\end{array}$}} & \multicolumn{3}{|c|}{ Result from BFL } & \multicolumn{3}{|c|}{ Result from FGIR fitting } \\
\hline & & $\begin{array}{l}\text { Age } \\
\text { (Ma) }\end{array}$ & Initial Ratio & MSWD & $\begin{array}{l}\text { Age Range } \\
\text { for FGIR } \\
\text { (Ma) }\end{array}$ & $\begin{array}{l}\text { Mean Age } \\
\text { (Ma) }\end{array}$ & Initial Ratio \\
\hline \multirow[t]{6}{*}{362514} & 500 & $2527 \pm 71$ & $0.508896 \pm 62$ & 0.58 & $2480-2512$ & $2496 \pm 16$ & $0.508922 \pm 27$ \\
\hline & 500 & $2533 \pm 74$ & $0.508893 \pm 63$ & 0.64 & $2498-2504$ & $2501 \pm 3$ & $0.508917 \pm 27$ \\
\hline & 500 & $2520 \pm 73$ & $0.508902 \pm 63$ & 0.79 & $2499-2512$ & $2505.5 \pm 6.5$ & $0.508914 \pm 29$ \\
\hline & 800 & $2531 \pm 76$ & $0.508893 \pm 65$ & 0.18 & $2497-2517$ & $2507 \pm 10$ & $0.508892 \pm 16$ \\
\hline & 800 & $2516 \pm 71$ & $0.508906 \pm 61$ & 0.22 & 2498-2502 & $2500 \pm 2$ & $0.508918 \pm 16$ \\
\hline & 800 & $2504 \pm 68$ & $0.508915 \pm 57$ & 0.26 & $2496-2501$ & $2498.5 \pm 2.5$ & $0.508920 \pm 16$ \\
\hline \multirow[t]{6}{*}{426513} & 500 & $2540 \pm 70$ & $0.508886 \pm 59$ & 0.47 & $2492-2515$ & $2503.5 \pm 11.5$ & $0.508913 \pm 26$ \\
\hline & 500 & $2537 \pm 74$ & $0.508890 \pm 62$ & 0.58 & $2484-2502$ & $2493 \pm 9$ & $0.508921 \pm 27$ \\
\hline & 500 & $2516 \pm 71$ & $0.508905 \pm 61$ & 0.7 & $2497-2506$ & $2501.5 \pm 4.5$ & $0.508915 \pm 26$ \\
\hline & 800 & $2520 \pm 70$ & $0.508903 \pm 59$ & 0.16 & $2498-2501$ & $2499.5 \pm 1.5$ & $0.508919 \pm 14$ \\
\hline & 800 & $2516 \pm 73$ & $0.508906 \pm 64$ & 0.2 & 2494-2502 & $2498 \pm 4$ & $0.508920 \pm 15$ \\
\hline & 800 & $2506 \pm 73$ & $0.508914 \pm 63$ & 0.24 & 2494-2501 & $2497.5 \pm 3.5$ & $0.508921 \pm 15$ \\
\hline \multirow[t]{6}{*}{451623} & 500 & $2528 \pm 75$ & $0.508895 \pm 64$ & 0.45 & $2498-2518$ & $2508 \pm 10$ & $0.508912 \pm 24$ \\
\hline & 500 & $2520 \pm 72$ & $0.508902 \pm 61$ & 0.55 & 2488-2509 & $2498.5 \pm 10.5$ & $0.508920 \pm 25$ \\
\hline & 500 & $2526 \pm 73$ & $0.508898 \pm 61$ & 0.65 & $2491-2506$ & $2498.5 \pm 7.5$ & $0.508920 \pm 26$ \\
\hline & 800 & $2520 \pm 72$ & $0.508903 \pm 61$ & 0.15 & $2496-2510$ & $2503 \pm 7$ & $0.508916 \pm 14$ \\
\hline & 800 & $2514 \pm 73$ & $0.508907 \pm 61$ & 0.18 & 2499-2507 & $2503 \pm 4$ & $0.508917 \pm 14$ \\
\hline & 800 & $2506 \pm 76$ & $0.508914 \pm 66$ & 0.21 & $2498-2508$ & $2503 \pm 5$ & $0.508917 \pm 14$ \\
\hline
\end{tabular}


Table A10. Application of FGIR to derive accurate ages from Rb-Sr data that give MSWD > 1. The data used in the calculations of 2500 Ma BFLs and other BFLs in Table A6 have been used to arrive at the ages based on FGIR as summarized in Table A7.

\begin{tabular}{|c|c|c|c|c|c|c|}
\hline $\begin{array}{c}\text { Layer } \\
\text { Relation } \\
\text { (Reset step) }\end{array}$ & $\begin{array}{c}2500 \mathrm{Ma} \\
\text { BFLs } \\
(\mathrm{MSWD}) *\end{array}$ & $\begin{array}{l}\text { Age Range } \\
\text { of FGIR } \\
2500 \mathrm{Ma}\end{array}$ & $\begin{array}{l}\text { Mean Age } \\
\text { (Ma) from } \\
\text { FGIR }\end{array}$ & $\begin{array}{l}\text { Other BFLs } \\
\text { (MSWD)* }\end{array}$ & $\begin{array}{l}\text { Age Range } \\
\text { of FGIR } \\
\text { Other BFLs }\end{array}$ & $\begin{array}{l}\text { Mean Age } \\
\text { (Ma) from } \\
\text { FGIR }\end{array}$ \\
\hline 146532 & $\begin{array}{c}2500 \pm 24(10.2) \\
2500 \pm 20(14) \\
2500 \pm 18(28)\end{array}$ & $\begin{array}{l}2495-2505 \\
2499.4-2504 \\
2497-2501.3\end{array}$ & $\begin{array}{l}2500 \pm 5 \\
2501.5 \pm 2.5 \\
2499 \pm 2\end{array}$ & $\begin{array}{l}2511 \pm 18(9.6) \\
2496 \pm 24(10) \\
2514 \pm 21(10.8)\end{array}$ & $\begin{array}{l}2499-2502 \\
2498-2503 \\
2496-2500.7\end{array}$ & $\begin{array}{l}2500.5 \pm 1.5 \\
2500.5 \pm 2.5 \\
2498.5 \pm 2.5\end{array}$ \\
\hline (1000) & $\begin{array}{l}2500 \pm 15(7.7) \\
2500 \pm 13(16) \\
2500 \pm 12(28)\end{array}$ & $\begin{array}{l}2499-2501 \\
2498-2501 \\
2499.7-2501\end{array}$ & $\begin{array}{l}2500 \pm 1 \\
2499.5 \pm 1.5 \\
2500.5 \pm 0.5\end{array}$ & $\begin{array}{l}2495 \pm 17(3.7) \\
2505 \pm 18(4.4) \\
2508 \pm 13(4.9)\end{array}$ & $\begin{array}{l}2498-2506 \\
2499.3-2503 \\
2498-2503\end{array}$ & $\begin{array}{l}2502 \pm 4 \\
2501 \pm 2 \\
2500.5 \pm 2.5\end{array}$ \\
\hline 246513 & $\begin{array}{l}2500 \pm 16(5.4) \\
2500 \pm 12(15) \\
2500 \pm 13(22)\end{array}$ & $\begin{array}{l}2498.7-2500.4 \\
2499.8-2502.9 \\
2499.1-2503\end{array}$ & $\begin{array}{l}2499 \pm 1.3 \\
2501 \pm 1.5 \\
2501 \pm 2\end{array}$ & $\begin{array}{l}2510 \pm 15(2.5) \\
2507 \pm 13(2.9) \\
2509 \pm 14(3.4)\end{array}$ & $\begin{array}{l}2499-2502 \\
2497.7-2504 \\
2499.2-2500.8\end{array}$ & $\begin{array}{l}2500.5 \pm 1.5 \\
2501 \pm 3 \\
2500 \pm 1\end{array}$ \\
\hline (1000) & $\begin{array}{l}2500 \pm 14(1.9) \\
2500 \pm 11(5.1) \\
2500 \pm 11(9.3)\end{array}$ & $\begin{array}{l}2497.7-2501.1 \\
2499.1-2500.4 \\
2499-2501.9\end{array}$ & $\begin{array}{l}2499.5 \pm 1.5 \\
2499.5 \pm 0.5 \\
2500.5 \pm 1.5\end{array}$ & $\begin{array}{l}2507 \pm 12(1.9) \\
2493 \pm 9.8(2.1) \\
2506 \pm 8.8(1.6)\end{array}$ & $\begin{array}{l}2499.3-2501 \\
2499-2500.3 \\
2497.9-2501.4\end{array}$ & $\begin{array}{l}2500 \pm 1 \\
2499.5 \pm 0.5 \\
2499.5 \pm 1.5\end{array}$ \\
\hline 362514 & $\begin{array}{l}2500 \pm 18(5.6) \\
2500 \pm 12(9.0) \\
2500 \pm 15(12)\end{array}$ & $\begin{array}{l}2496-2501.9 \\
2499.4-2500.5 \\
2499-2502\end{array}$ & $\begin{array}{l}2499 \pm 3 \\
2500 \pm 0.5 \\
2500.5 \pm 1.5\end{array}$ & $\begin{array}{l}2509 \pm 19(2.7) \\
2510 \pm 15(2.7) \\
2508 \pm 18(3.5)\end{array}$ & $\begin{array}{l}2497.7-2504.5 \\
2497.6-2503.5 \\
2498.8-2502.4\end{array}$ & $\begin{array}{l}2501.5 \pm 2.5 \\
2500.5 \pm 3 \\
2500.5 \pm 1.5\end{array}$ \\
\hline (1000) & $\begin{array}{l}2500 \pm 14(2.8) \\
2500 \pm 12(4.1) \\
2500 \pm 12(5.5)\end{array}$ & $\begin{array}{l}2498.9-2501.4 \\
2499-2502.1 \\
2498.9-2501.5\end{array}$ & $\begin{array}{l}2500 \pm 1 \\
2500.5 \pm 1.5 \\
2500.3 \pm 1.2\end{array}$ & $\begin{array}{l}2508.6 \pm 6(1.5) \\
2506.6 \pm 8(1.8) \\
2503 \pm 12(2.4)\end{array}$ & $\begin{array}{l}2498.9-2502.4 \\
2498.7-2500.9 \\
2498.7-2502.6\end{array}$ & $\begin{array}{l}2500.5 \pm 1.5 \\
2500 \pm 1 \\
2500.5 \pm 1.5\end{array}$ \\
\hline 426513 & $\begin{array}{l}2500 \pm 28(32) \\
2500 \pm 25(43) \\
2500 \pm 21(44)\end{array}$ & $\begin{array}{l}2496-2503 \\
2496.7-2503.8 \\
2498.3-2503\end{array}$ & $\begin{array}{l}2499.5 \pm 3.5 \\
2500.5 \pm 3.5 \\
2500.5 \pm 2.5\end{array}$ & $\begin{array}{l}2519 \pm 24(10.2) \\
2515 \pm 27(11.2) \\
2523 \pm 34(12)\end{array}$ & $\begin{array}{l}2498.6-2504 \\
2492.1-2507.5 \\
2497.8-2500.8\end{array}$ & $\begin{array}{l}2501 \pm 3 \\
2500 \pm 8 \\
2499.5 \pm 1.5\end{array}$ \\
\hline (1000) & $\begin{array}{l}2500 \pm 18(13) \\
2500 \pm 17(15) \\
2500 \pm 17(45)\end{array}$ & $\begin{array}{l}2496-2502 \\
2497.8-2500.8 \\
2497.4-2502.3\end{array}$ & $\begin{array}{l}2499 \pm 3 \\
2499.5 \pm 1.5 \\
2500 \pm 2.5\end{array}$ & $\begin{array}{l}2516 \pm 16(4.4) \\
2511 \pm 21(5.5) \\
2507 \pm 25(6.2)\end{array}$ & $\begin{array}{l}2499.2-2502.6 \\
2497.6-2500.8 \\
2497.3-2500.8\end{array}$ & $\begin{array}{l}2500.5 \pm 1.5 \\
2499.5 \pm 1.5 \\
2499 \pm 2\end{array}$ \\
\hline 451623 & None & - & - & $\begin{array}{l}2538 \pm 61(36) \\
2548 \pm 83(53) \\
2522 \pm 53(223)\end{array}$ & $\begin{array}{l}2493-2503 \\
2495.5-2507.6 \\
2498.2-2502\end{array}$ & $\begin{array}{l}2498 \pm 5 \\
2502 \pm 6 \\
2500 \pm 2\end{array}$ \\
\hline (1000) & None & - & - & $\begin{array}{l}2523 \pm 30(20) \\
2511 \pm 32(39) \\
2513 \pm 35(69)\end{array}$ & $\begin{array}{l}2496-2507 \\
2499.2-2504 \\
2497.6-2503.8\end{array}$ & $\begin{array}{l}2501.5 \pm 5.5 \\
2501.5 \pm 2.5 \\
2501 \pm 3 \\
2501 \pm 3\end{array}$ \\
\hline
\end{tabular}




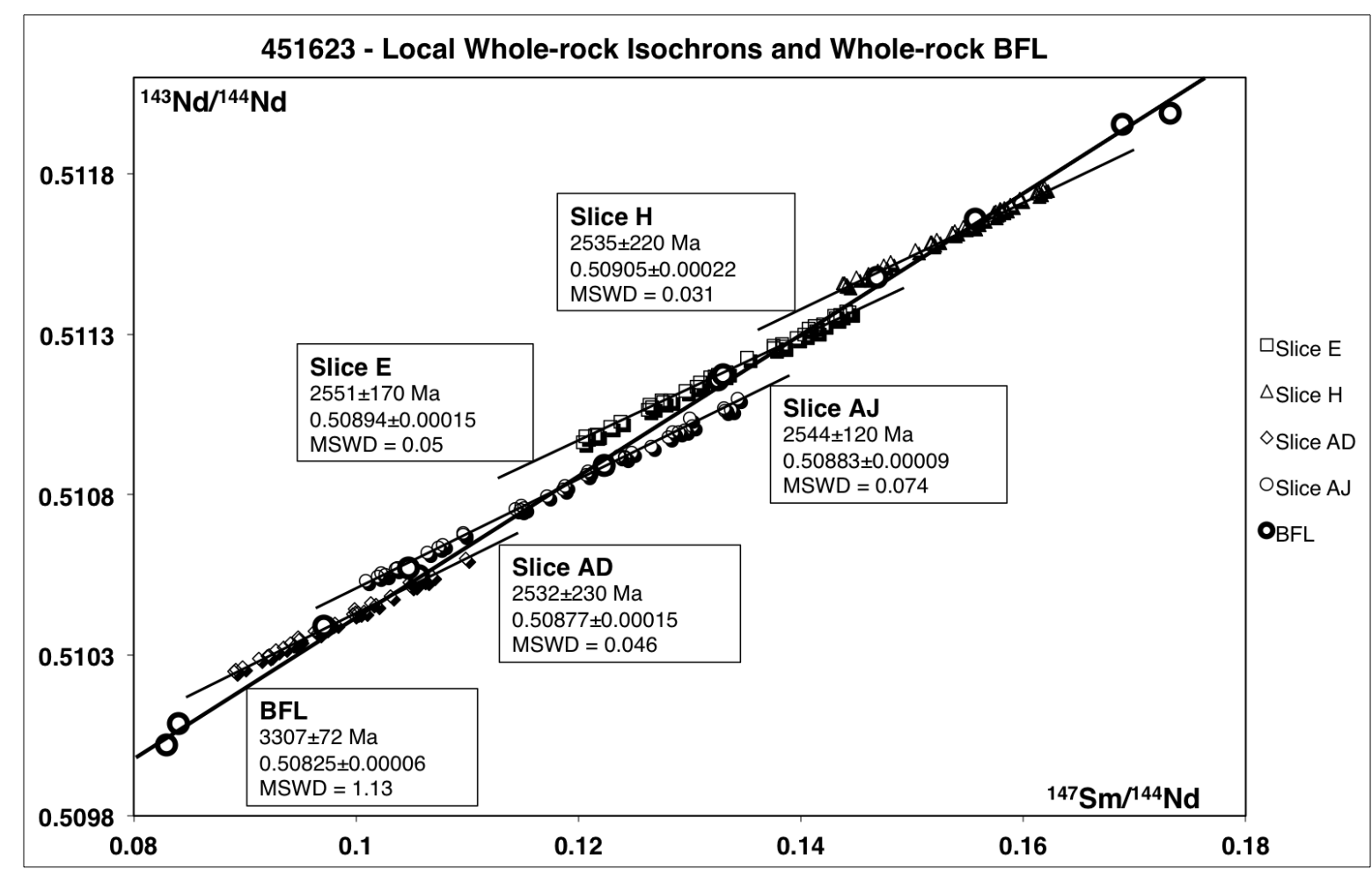

Fig. A7. A twelve-sample whole-rock BFL and four local whole-rock isochrons for slices $E, H, A D$ and $A J$ from mid stage 1 of 451623-333333. All twelve local isochrons are not shown to maintain clarity in the diagram but are given in Table Al1 below.

Table A11. Twelve-sample whole-rock BFL and local whole-rock isochrons for twelve slices from mid-stage 1. The same whole-rocks and slices from 451623-333333 are presented in Table Al for end of stage 1.

\begin{tabular}{|llllll|}
\hline BFL/Isochron & Age (Ma)* & Initial Ratio* & $\begin{array}{l}\text { MSWD (PoF) } \\
\mathbf{2 \sigma}=\mathbf{0 . 0 1 \%}\end{array}$ & $\begin{array}{l}\text { MSWD (PoF) } \\
\mathbf{2 \sigma}=\mathbf{0 . 0 0 4 4 \%}\end{array}$ & $\begin{array}{l}\text { MSWD (PoF) } \\
\mathbf{2 \sigma}=\mathbf{0 . 0 0 2 5 \%}\end{array}$ \\
\hline Whole-rocks BFL & $3307 \pm 72$ & $-1.72 \pm 1.18$ & $1.13(0.34)$ & $5.7(0)$ & $17(0)$ \\
Slice B & $2538 \pm 190$ & $-8.16 \pm 3.14$ & $0.058(1)$ & $0.3(1)$ & $0.9(0.64)$ \\
Slice E & $2551 \pm 170$ & $-7.63 \pm 2.95$ & $0.050(1)$ & $0.25(1)$ & $0.77(0.83)$ \\
Slice G & $2525 \pm 210$ & $-6.53 \pm 4.12$ & $0.061(1)$ & $0.31(1)$ & $0.93(0.58)$ \\
Slice H & $2535 \pm 220$ & $-5.88 \pm 4.32$ & $0.031(1)$ & $0.16(1)$ & $0.48(0.996)$ \\
Slice O & $2520 \pm 190$ & $-14.12 \pm 1.96$ & $0.0053(1)$ & $0.027(1)$ & $0.084(1)$ \\
Slice Q & $2509 \pm 220$ & $-13.62 \pm 2.36$ & $0.0088(1)$ & $0.046(1)$ & $0.14(1)$ \\
Slice T & $2533 \pm 210$ & $-5.15 \pm 4.71$ & $0.017(1)$ & $0.085(1)$ & $0.26(1)$ \\
Slice U & $2516 \pm 230$ & $-4.41 \pm 5.1$ & $0.0054(1)$ & $0.027(1)$ & $0.082(1)$ \\
Slice Z & $2560 \pm 200$ & $-10.94 \pm 2.55$ & $0.017(1)$ & $0.087(1)$ & $0.26(1)$ \\
Slice AD & $2532 \pm 230$ & $-11.46 \pm 2.94$ & $0.046(1)$ & $0.24(1)$ & $0.73(0.88)$ \\
Slice AF & $2566 \pm 110$ & $-10.04 \pm 1.69$ & $0.051(1)$ & $0.26(1)$ & $0.8(0.79)$ \\
Slice AJ & $2544 \pm 120$ & $-9.86 \pm 1.87$ & $0.074(1)$ & $0.38(1)$ & $1.16(0.24)$ \\
\hline
\end{tabular}

$*$ Age and Initial eNd (T) given at $2 \sigma=0.01 \%$ of ${ }^{143} \mathrm{Nd} /{ }^{144} \mathrm{Nd}$ and $0.1 \%$ of ${ }^{147} \mathrm{Sm} /{ }^{144} \mathrm{Nd}$. 


\section{DESCRIPTION OF SUPPLEMENTARY MOVIES}

\section{MOVIE S1.}

This movie shows all three stages of the process of isochron translation described in the text, occurring during resetting of a $3500 \mathrm{Ma} \mathrm{Rb}-\mathrm{Sr}$ isochron at $2500 \mathrm{Ma}$ for the layer arrangement 362514-333333. The letters $\mathrm{H} 1, \mathrm{H} 2$ along $\mathrm{H} 3$ at the end of title line of each frame helps to identify the three stages of isochron translation, respectively. The legend identifies the layer arrangement 362514 from top to bottom. To reduce its size, the movie $\mathrm{S} 1$ has been created using increasing rates of isotopic exchange during the three stages of isochron translation, choosing frames at increasing time intervals. That gives the false impression that isotopic exchanges are happening at a regular rate throughout the resetting process.

The following are noteworthy in the Movie S1:

1. The scattering of data belonging to each layer into distinct aggregates at the on-set of isotopic resetting. Towards the end of the stage 1, the data of each layer are scattered in a wider area, and one finds vaguely defined horizontal lines of data within each scatter suggesting beginning of local isotopic homogenization in layer parallel slabs of each layer. By that time, initial ratios of local isotopic homogenization show the widest range.

2. In the stage 2, horizontal lines of data of local homogenization become well-defined within every layer as resetting progresses. The initial ratios of local homogenization within subsets of each and every layer continue to modify throughout the stage 2 , and while those groups of subsets of layers translate in the diagram, their initial ratios overlap within this stage. Figure 2 shows details of these changes happening within every layer in the arrangement 362514-333333 throughout stage 2 until the Culmination of Isochron
Translation (CIT) is reached. Figure 2 has been created using data from a simulation which used the smallest rate of isotopic exchange, thus, 70,000 steps to reach CIT. Towards the end of the stage 2, short-lived, complete isotopic homogenization of all samples of all slabs in layers 3, 1, and 4, respectively, can be seen before reaching the CIT. At the CIT the arrangement of data of the different layers within the isochron diagram follow their field relationship to define a daughter isotopic Field Gradient of Initial Ratios (FGIR) across all the layers.

3. Throughout stage 3 , relative positions of groups and subsets of isotopic data of the different layers remain fixed in the isochron diagram, and the initial ratios of the subsets and groups do not overlap. The Movie shows homogenization of ${ }^{87} \mathrm{Sr} /{ }^{86} \mathrm{Sr}$ ratios at the fifth decimal point in all six layers towards the end of the stage 3 of isochron translation. The FGIR of local isotopic homogenization persists and the gradient still remains across the layers beyond the fifth decimal point. Thus, FGIR is characteristic of the third stage.

\section{MOVIE S2.}

This movie shows all three stages of isochron translation as observed today and has been created using frames that correspond with those in Movie S1. The T1, T2 and T3 at the end of the title of each frame help to identify the three stages. However, unlike in the Movie S1, the three stages cannot be distinguished in this movie although the time gap between protolith and resetting ages is $1000 \mathrm{Ma}$. This is even more difficult whenever the time gap between the primary and secondary events is small, particularly in the Sm-Nd system.

\section{PROTOLITH DATA:}

$\mathrm{Rb}-\mathrm{Sr}$ and $\mathrm{Sm}-\mathrm{Nd}$ data of protoliths used in the simulations are summarized in the supplementary tables provided. 